\title{
Hyperspectral Coral Reef Classification of Bonaire
}

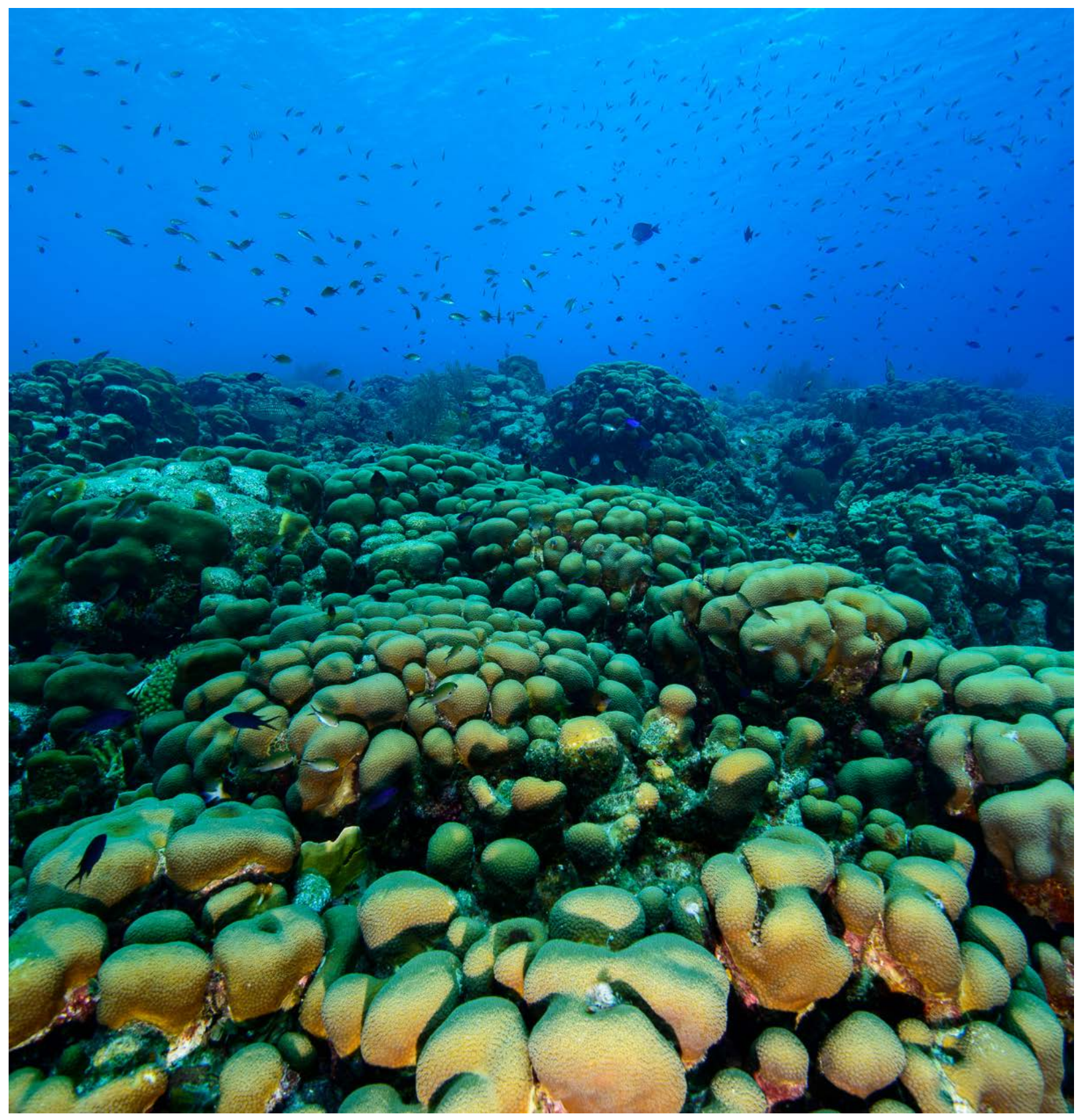

Authors:

Sander Mücher ${ }^{1}$, Juha Suomalainen², J ohn Stuiver ${ }^{2}$, Erik Meesters ${ }^{3}$

${ }^{1}$ Wageningen Environmental Research, WUR, Droevendaalsesteeg 3, $6700 \mathrm{AA}$, Wageningen ${ }^{2}$ Wageningen University, WUR, Laboratory of Geo-Information Science and Remote Sensing, Droevendaalsesteeg 3, 6700 AA, Wageningen.

${ }^{3}$ Wageningen Marine Research, WUR, Ankerpark 27, 1781 AG, Den Helder. 
This research project was carried out by Wageningen Marine and Environmental Research at the request of and with funding from the Ministry of Economic Affairs for the purposes of Policy Support Research Theme Caribbean Netherlands (project no. BO-11-019.02-022).

Wageningen Marine Research \& Wageningen Environmental Research Wageningen, January 2017

Wageningen Marine Research report C062/17

(C) 2017 Wageningen Marine Research \& Wageningen Environmental Research, Wageningen UR

Wageningen Marine Research institute of Stichting Wageningen Research is registered in the Dutch traderecord nr. 09098104, BTW nr. NL 806511618
The Management of Wageningen Marine Research is not responsible for resulting damage, as well as for damage resulting from the application of results or research obtained by Wageningen Marine Research, its clients or any claims related to the application of information found within its research. This report has been made on the request of the client and is wholly the client's property. This report may not be reproduced and/or published partially or in its entirety without the express written consent of the client.

\footnotetext{
A 4_3 2 V24
} 
Sander Mücher, Juha Suomalainen, John Stuiver, Erik Meesters, 2017. Hyperspectral Coral Reef Classification of Bonaire. Wageningen, Wageningen Marine Research (University \& Research centre), Wageningen Marine Research report C062/17. 38 pp.; number of tables 2; number of ref. 14.

Doi: https://doi.org/10.18174/422722

Keywords: Remote sensing, coral reef mapping, Bonaire, coral reef.

Client: $\quad$ Ministry of Economic Affairs

Attn.: G. Schutjes

Postbus 20401

2500 EK Den Haag

BO-11-019.02-022

Wageningen Marine Research is ISO 9001:2008 certified.

Photo cover: Made by Erik Meesters on 3 October 2014 close to Petries Pillar. 



\section{Contents}

\section{Summary}

$1 \quad$ Introduction

$2 \quad$ Hyperspectral data processing

2.1 Hyperspectral Mapping System (HYMSY) 10

$\begin{array}{lll}2.2 & \text { Airborne hyperspectral campaign } & 10\end{array}$

$\begin{array}{lll}2.3 & \text { HYMSY processing and products } & 11\end{array}$

2.3.1 Reflectance calibration 11

2.3.2 Georectification 11

$\begin{array}{lll}2.4 & \text { Water column corrections } & 14\end{array}$

2.4.1 Theory 15

2.4.2 Water column depth data 16

$\begin{array}{ll}2.4 .3 & \text { Glare/deep water spectrum }\end{array}$

2.4.4 Water transmittance 20

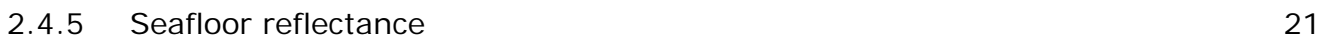

2.4.6 Selection of spectral bands for coral reef classification 21

3 Hyperspectral Coral Reef Classification (HCRC) 23

3.1 Classification method 23

3.2 Benthic habitat types $\quad 23$

3.2.1 Pavement or hard bottom 24

3.2.2 Rubble $\quad 24$

$\begin{array}{lll}3.2 .3 \text { Sand } & 24\end{array}$

3.2.4 Soft corals (gorgonians)

$\begin{array}{ll}3.2 .5 \text { Hard corals } & 25\end{array}$

$\begin{array}{llr}3.3 & \text { Ground-truthing } & 25\end{array}$

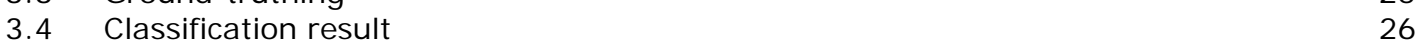

$\begin{array}{ll}3.5 & \text { Assessment of the HCRC accuracy } \\ \end{array}$

4 Conclusions \& Recommendations $\quad 35$

$5 \quad$ Acknowledgements $\quad 36$

$\begin{array}{lr}\text { References } & 37\end{array}$ 


\section{Summary}

In order to update the 1985 atlas of Bonaire's coral reefs (Van Duyl, 1985), a hyperspectral mapping campaign was performed in October 2013 using the Wageningen UR Hyperspectral Mapping System (HYMSY) with 101 spectral channels. In June 2016, with the help of STINAPA Bonaire, Sander Mücher and Erik Meesters were able to perform an extensive diving campaign to collect in-situ information in 20 transects perpendicular to the coastline across the western coast. Detailed photographs of the sea bottom were taken by diving to a depth of 20-30 meters, then progressing shallower towards the coast. Photographs were geotagged by another person snorkelling exactly above the diver with a GPS in a waterproof box and making overview pictures of the sea bottom as well.

This in-situ information was used to interpret the hyperspectral imagery made by the HYMSY camera. In order to interpret the data more consistently, the hyperspectral data were corrected for the water depth into at-ground-reflectance factor units. A bathymetric model was used for the calibration of the hyperspectral imagery based on a former field campaign by measuring water depth at specific locations along the western coast. The final bathymetric model was based on extrapolation of the terrestrial digital elevation model by fitting the DEM with additional in-situ bathymetric measurements at sea. A more detailed bathymetric model may improve the calibration of the hyperspectral data with a 1-meter spatial resolution.

Due to the limited penetration of green and red light through the water, it was decided to use only the first 15 hyperspectral bands in the violet-blue -cyan till green range (Band $1=450.0 \mathrm{~nm}$ to Band $15=$ $520.0 \mathrm{~nm}$ ). This means that spectral measurements can be made to a maximum depth of 20 to 30 meters.

The hyperspectral reef classification defines 12 classes including sand, pavement, rubble, soft and hard corals, and various mixtures of these at a pixel level of 1-meter spatial resolution. Due to their spectral similarity, corals and algae remain difficult to separate. 


\section{Introduction}

The Dutch Caribbean island Bonaire has protected its marine resources for more than 35 years and has been ranked as one of the Caribbean's top dive destinations much due to its wide range of easily accessible diving sites, clear waters and a relatively healthy coral reef ecosystem. The importance of coral reefs is multifunctional. They provide many ecosystem services, not only to attract tourism and therefore income, but they also act as a natural barrier to protect the coast, and they form habitat for many species, providing food as well. The total economic value of Bonaire's nature including its coral reef has been estimated at more than 100 milion dollar per year (WKICS 2013).

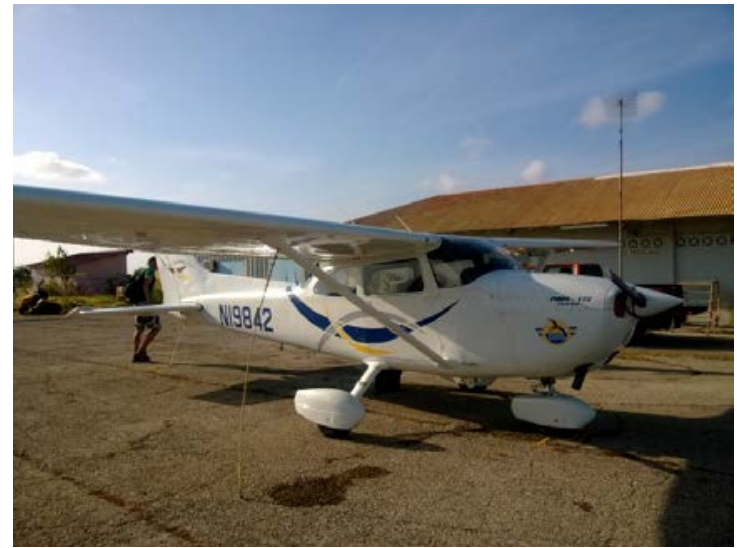

The general consensus is that the extent and biodiversity of Bonaire's coral reef is decreasing due to local and regional anthropogenic and global climate pressures (Bak et al. 2005, Newman et al. 2015, De Bakker et al. 2016, de Bakker et al. 2017). However, the last extensive study of the coral coverage of the whole reef ecosystem was performed in 1985 by Van Duyl who created an underwater atlas of Bonaire and Curaçao (Duyl 1985). In order to update this atlas of Bonaire's coral reefs, a hyperspectral mapping campaign was performed in October 2013 using the Wageningen UR Hyperspectral Mapping System (HYMSY) with 101 spectral channels.

Figure 1. Hyperspectral mapping campaign from airplaine and by using a kite.

Several additional research activities were necessary before the hyperspectral data could be processed into maps. First bathymetric data needed to be collected to make a bathymetric model for the west side of the island. With this model the colour bands of the hyperspectral data needed to be corrected as water depth greatly influences the colours that the camera recorded. Next an extensive ground-truthing campaign was necessary to classify the hyperspectral data into useful categories.

In J une 2016, with the help of STI NAPA Bonaire, Sander Mücher and Erik Meesters were able to perform an extensive ground-truthing campaign to collect in-situ information in 20 transects perpendicular to the coastline across the western coast of the island. Detailed photographs of the sea bottom were taken by diving from a depth of 20-30 meters towards the shore. Photographs were geotagged by another person snorkelling exactly above the diver with a GPS in a waterproof box and making overview pictures of the sea bottom as well. This in-situ information was used to interpret the hyperspectral imagery made by the HYMSY camera.

The HYMSY camera consists of a custom pushbroom spectrometer (range 450-950nm, FWHM 9nm, 20 lines/s, 328 pixels/line), a consumer camera (collecting 16MPix raw image every 2 seconds), a GPS-Inertia Navigation System (GPS-INS), and synchronization and data storage units (Figure 1). The weight of the system at take-off is $2.0 \mathrm{~kg}$ allowing it to be mounted on varying platforms. On Bonaire the system was flown on two platforms: 1 ) on a Cessna airplane to provide a coverage for the whole coastline, and 2) on a kite pulled by boat or car at lower altitude than the Cessna to provide a subset coverage in higher resolution. With the Cessna the whole west coast of the island was mapped. The Aerial images were collected at $15 \mathrm{~cm}$ ground sampling distance (GSD) and the hyperspectral data in $1 \mathrm{~m}$ GSD. The data were mosaicked and geo-rectified to form hyperspectral maps of the western and southern coastal area of Bonaire (Figure 2 ). 


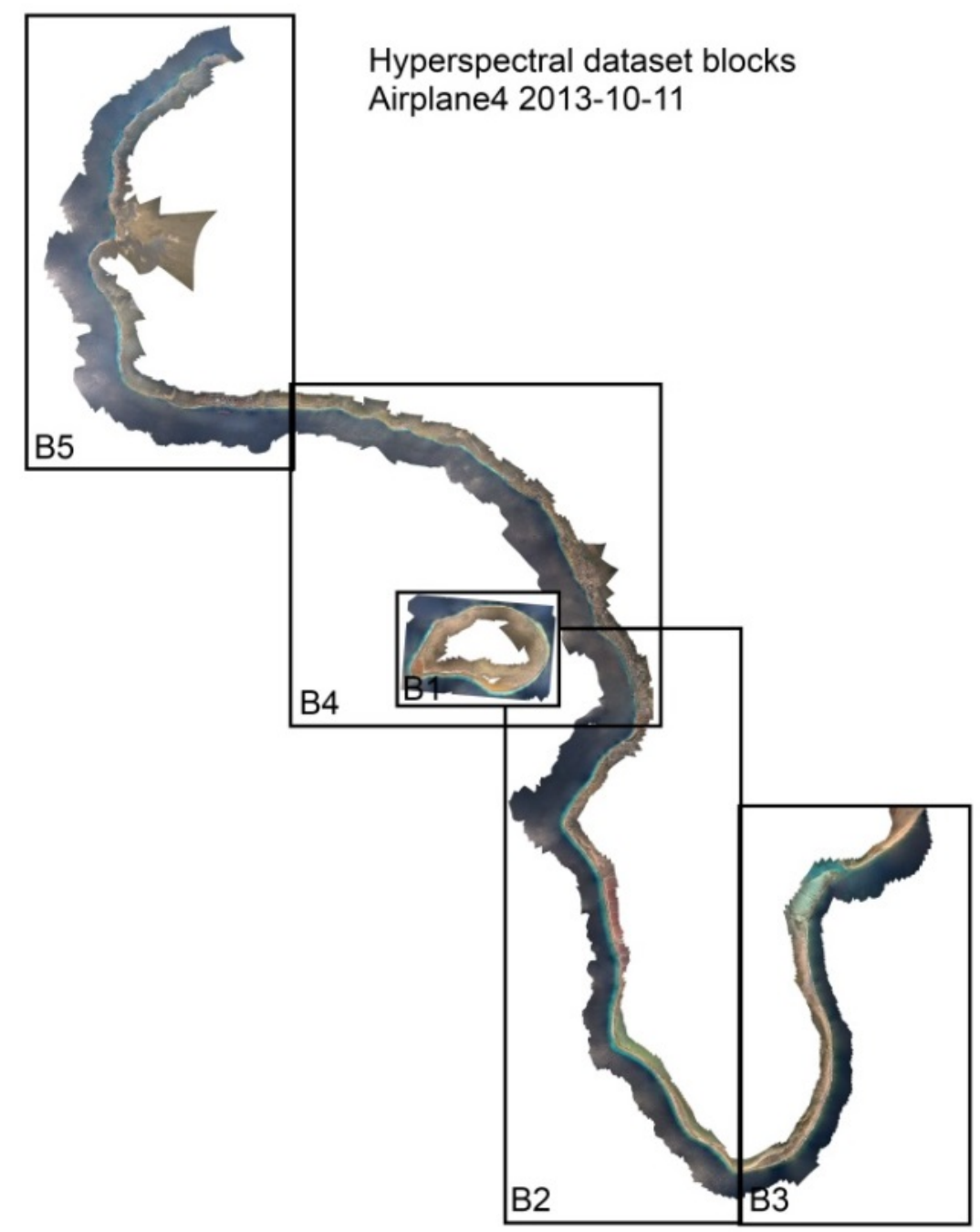

Figure 2. The hyperspectral data were recorded on 11th October 2013 by the HYMSY camera mounted on a Cessna airplane and were mosaicked and georectified to form a hyperspectral image of the coastline of Bonaire. Data were processed in 5 hyperspectral dataset blocks.

In order to interpret the data more consistently, the hyperspectral data were corrected for water depth into at-ground-reflectance factor units. A bathymetric model was used for the calibration of the hyperspectral imagery based on a former field campaign by measuring water depth at specific locations along the western coast. The final bathymetric model that we used was based on extrapolation of the terrestrial digital elevation model through fitting with additional in-situ bathymetric measurements at sea. A more detailed bathymetric model would of course have been preferred to calibrate the hyperspectral data with a 1-meter spatial resolution. Due to the limited penetration of green and red light through the water, it was decided to use only the first 15 hyperspectral bands in the violet-blue - cyan till green range (Band $1=450.0 \mathrm{~nm}$ to Band $15=520.0 \mathrm{~nm}$ ). This means that spectral measurements can be made to a maximum depth of 20 - 30 meters. The hyperspectral Coral Reef Classification (HCRC) is divided into simple classes such as sand, pavement, rubble, soft and hard corals and various mixtures of these classes at 1meter spatial resolution (Figure 4). A real validation of the HCRC is unfortunately not included in this report, due to lack of comparable data. 


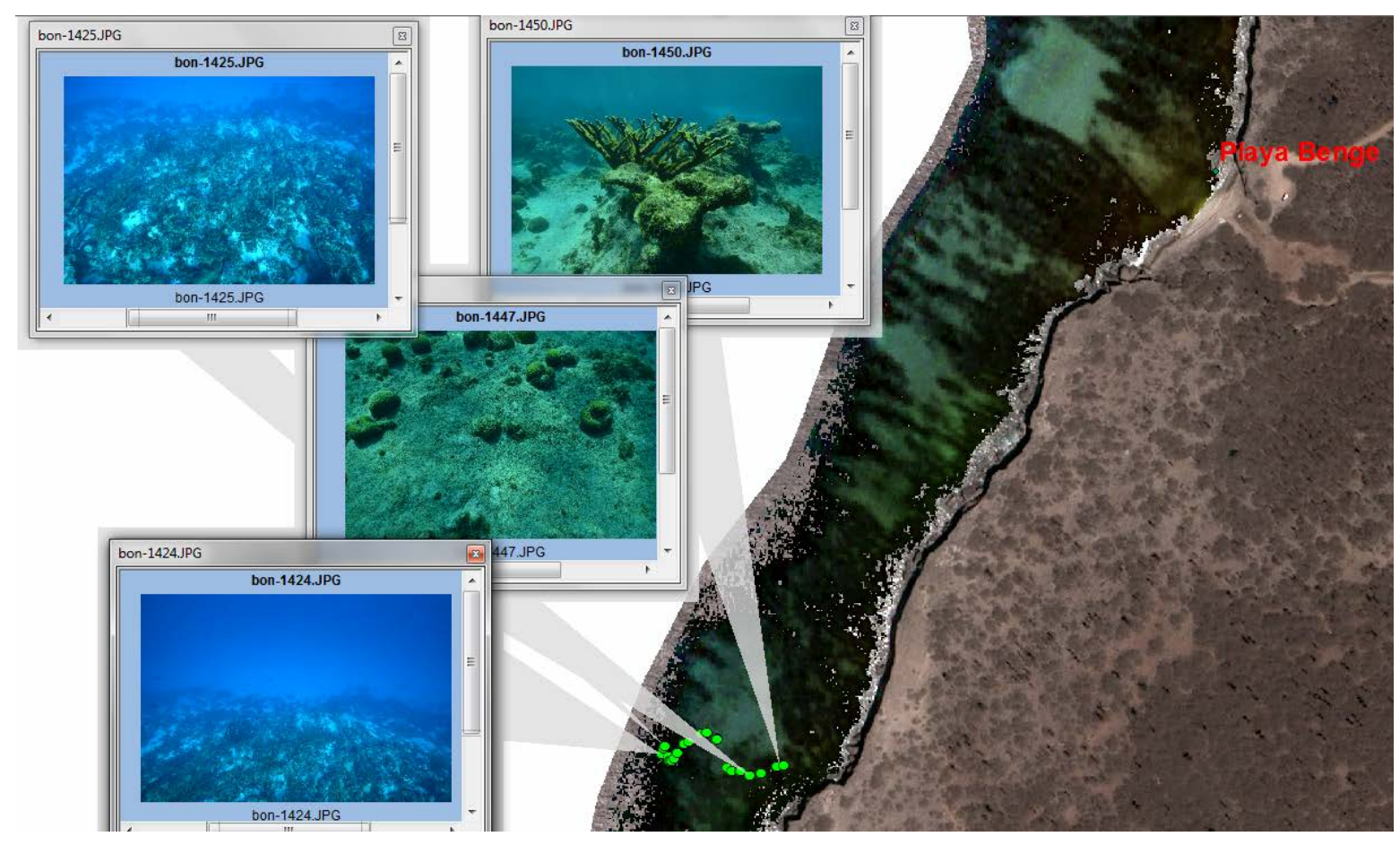

Figure 3 HYMSY hyperspectral spectral imagery (RGB: $520 \mathrm{~nm}, 480 \mathrm{~nm}, 476 \mathrm{~nm}$ ) with green dots showing the most northerly diving transect. Image (mainly the land section) behind the hyperspectral image is a Pleiades satellite image (brown to greyish colours) with $50 \mathrm{~cm}$ resolution.

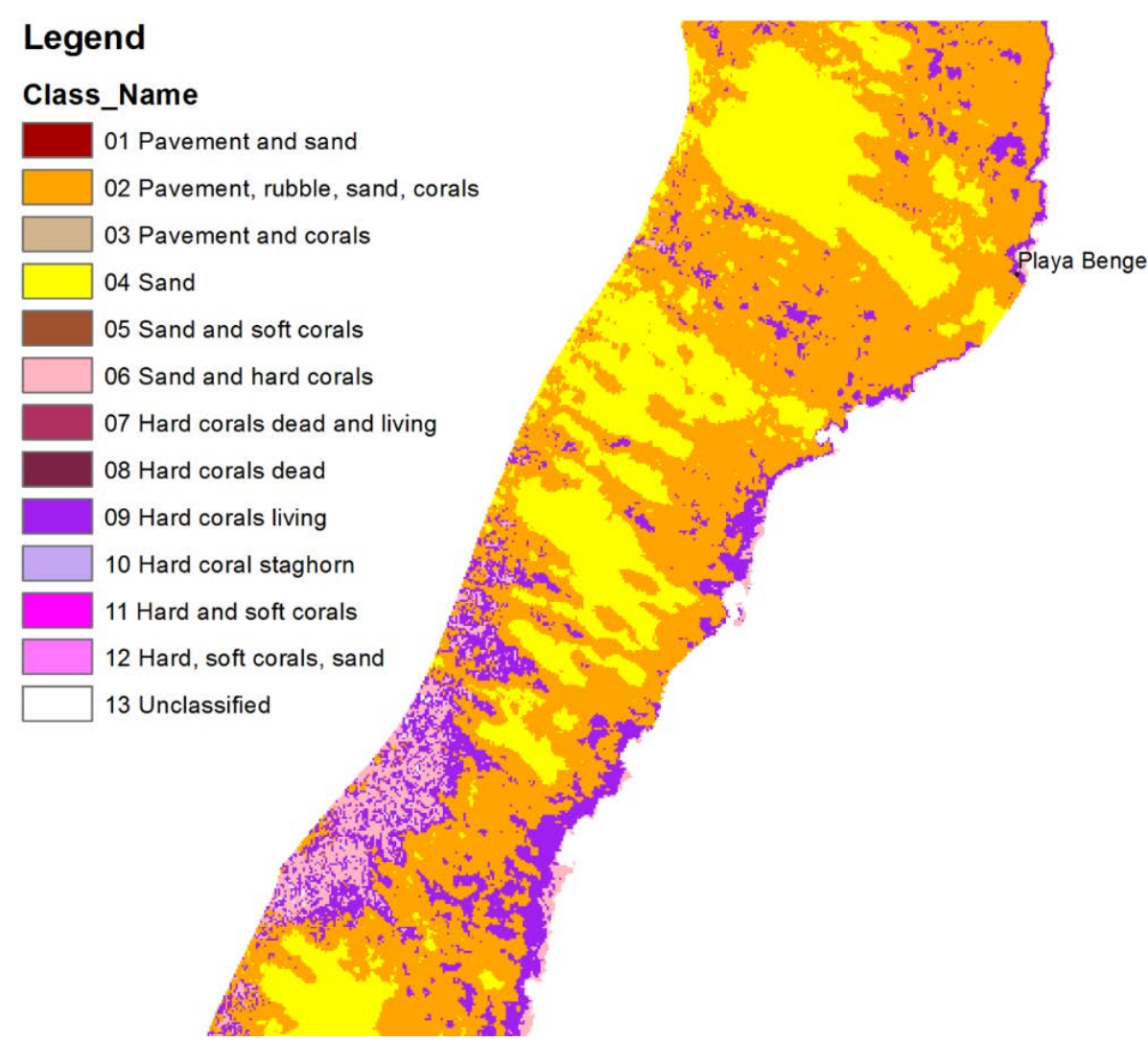

Figure 4. Detail of the Hyperspectral Coral Reef Classification (HCRC) near Playa Benge on the Northern coast of Bonaire. 


\section{Hyperspectral data processing}

\subsection{Hyperspectral Mapping System (HYMSY)}

The remote sensing sensor used in Bonaire's airborne campaign in 2013 was the HYMSY system that has been developed at the Unmanned Aerial Remote Sensing Facility of the Wageningen University \& Research (www.wur.eu/uarsf). Suomalainen et al. (2014) describes in detail the HYMSY and the standard processing chain. In short, HYMSY is a pushbroom spectrometer system capable of producing reflectance factor spectrum maps in a range of $450-950 \mathrm{~nm}$ at $9 \mathrm{~nm}$ spectral resolution. In practice it means that you have a hyperspectral camera with 101 spectral channels. The pixel size depends on the flight altitude and varies typically between $10 \mathrm{~cm}$ and $1 \mathrm{~m}$. Additional to the hyperspectral sensor, the HYMSY has also a normal Red-Green-Blue (RGB) photo camera. The RGB images can be used to produce high resolution $(1-15 \mathrm{~cm})$ orthophoto maps and photogrammetric 3D models of the mapped area.

\subsection{Airborne hyperspectral campaign}

The mapping campaign in Bonaire was performed in October 2013. The primary dataset was collected on $11^{\text {th }}$ of October 2013 by mounting the HYMSY system on a Cessna airplane and flying at $400 \mathrm{~m}$ altitude along the coastlines on the whole western half of the island. This area contains practically the main coral reefs on Bonaire. Since the east coast is subjected to heavy waves the development of extensive reef platforms appears much less developed than on the leeward side. This flight allowed us to map the reefs with a hyperspectral pixel size of $1 \mathrm{~m}$. In practice this means that the size of the smallest separable object is approximately $2 \mathrm{~m}$. The RGB orthophoto was generated with $15 \mathrm{~cm}$ pixel size. In addition to this airplane based imagery, other higher resolution datasets were collected as well by hanging the HYMSY on a kite, and pulling it behind a car along the coastal road or on a boat on the water. These datasets proved to be challenging to geoprocess due to water refraction distortions in the imagery and instability of the kite platform. Thus they were not processed completely and the efforts on data analysis were concentrated on utilizing the airplane based data. 


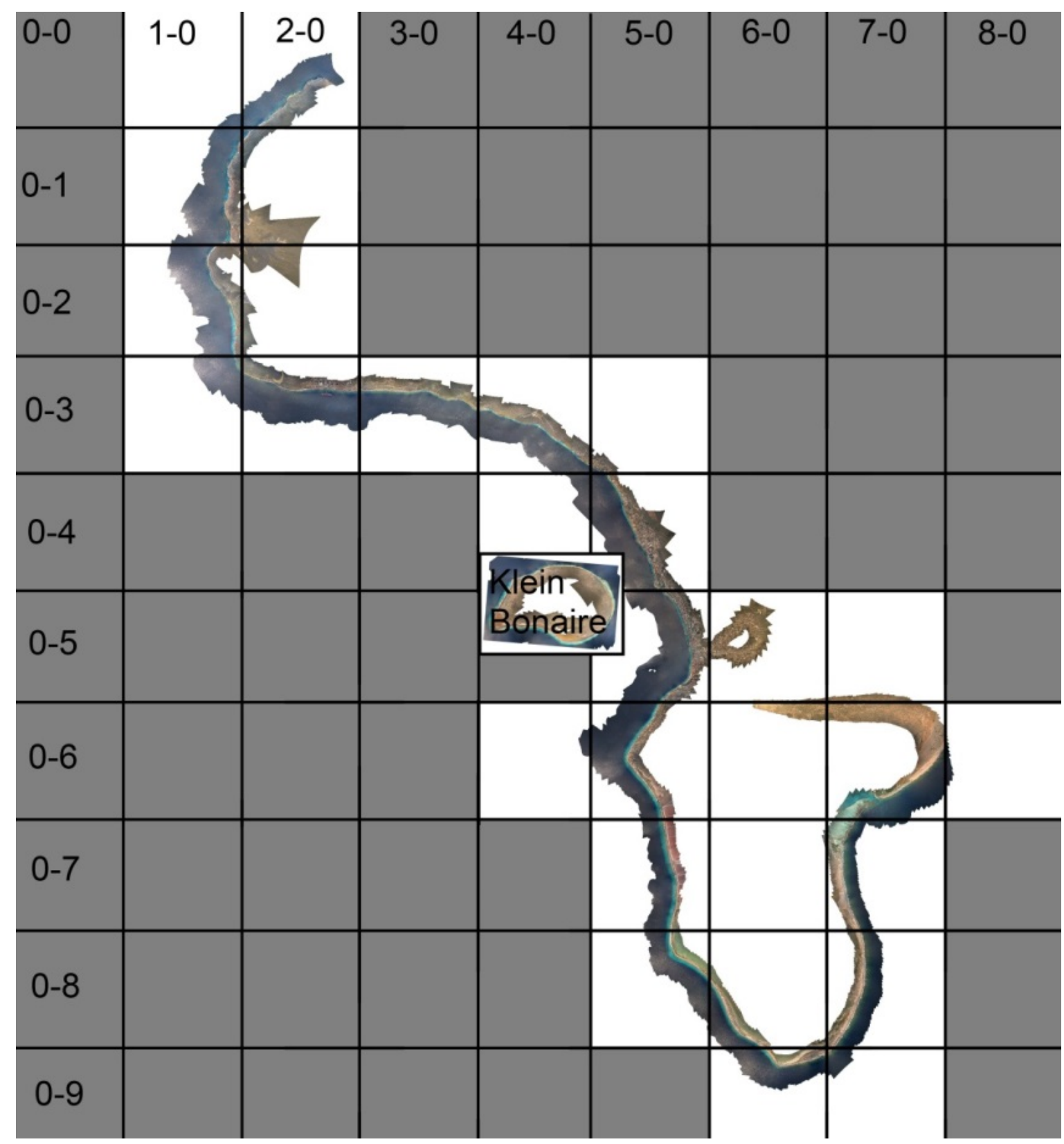

Figure 5. Large scale view of the orthophoto from the airplane based main dataset. The hyperspectral data covers a slightly narrower swath than the orthophoto. The numbers on edges refer to the separate image blocks in which the high-resolution data was stored in.

\subsection{HYMSY processing and products}

\subsubsection{Reflectance calibration}

As a first processing step, the intensities in the raw hyperspectral imagery were calibrated to reflectance factors using an empirical line method. For this purpose, we measured the reflectance factor spectrum of a concrete pier near the centrum of the town. Using the known reflectance of the pier, we converted the airborne radiances to reflectance factors. In good conditions the accuracy of such methodology is approximately $\pm 10 \%$. Unfortunately on all flights some clouds were present and thus some parts of the coastline were shadowed, while most of the coastline was mapped in good sunlit conditions. The shadowed areas had lower reflectance factors than expected. In these areas, the effect is estimated to be between $-10 \%$ and $-50 \%$ change to normal spectrum level. With available methods, it is not possible to correct for these shadows and we had to accept them as a feature in some subset areas of the data (Figure $6)$.

\subsubsection{Georectification}

After the basic radiometric processing, the dataset was georectified using first Agisoft Photoscan to georectify the photos and then using the ReSe PARGE module to georectify the hyperspectral data. Due to water refractions "moving" the underwater targets, it proved to be difficult for the Agisoft Photoscan to create a sensible 3D model of the terrain. The resulting orthophoto (Figure 7) was visually adequate but had in some parts of the island offsets of up to hundreds of meters in absolute coordinates. 
Even with such problems, we were able to produce in PARGE the hyperspectral map spatially matching well to this distorted orthophoto.

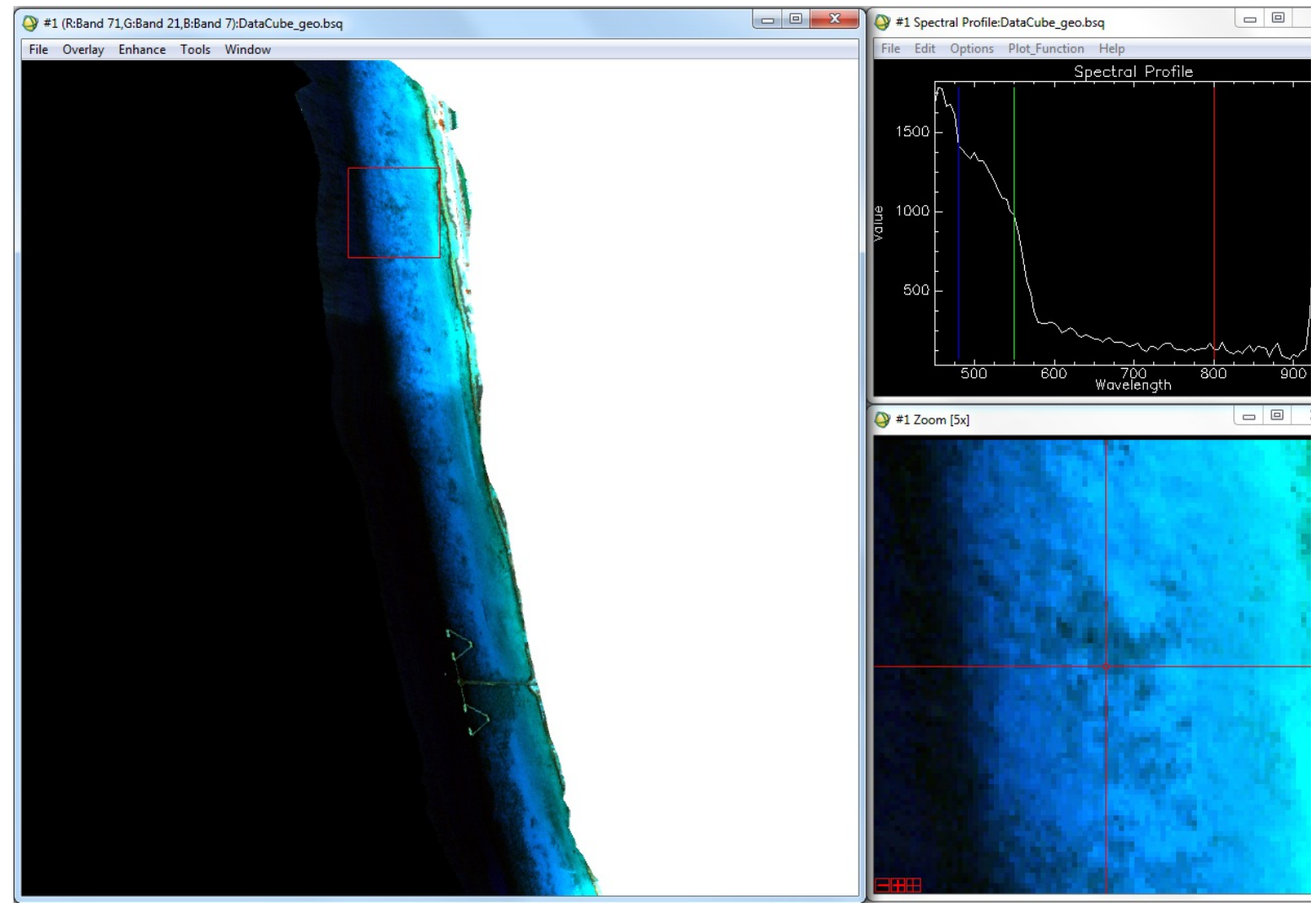

Figure 6. Example of the hyperspectral data at full resolution. The image shows also a shadow of a cloud present at lower part of this image. The upper right image shows the reflectance values over the complete electromagnetic spectrum from 450 - $950 \mathrm{~nm}$ for the indicated location at sea, also shown at the lower right image. No water column corrections have been performed at this stage. 


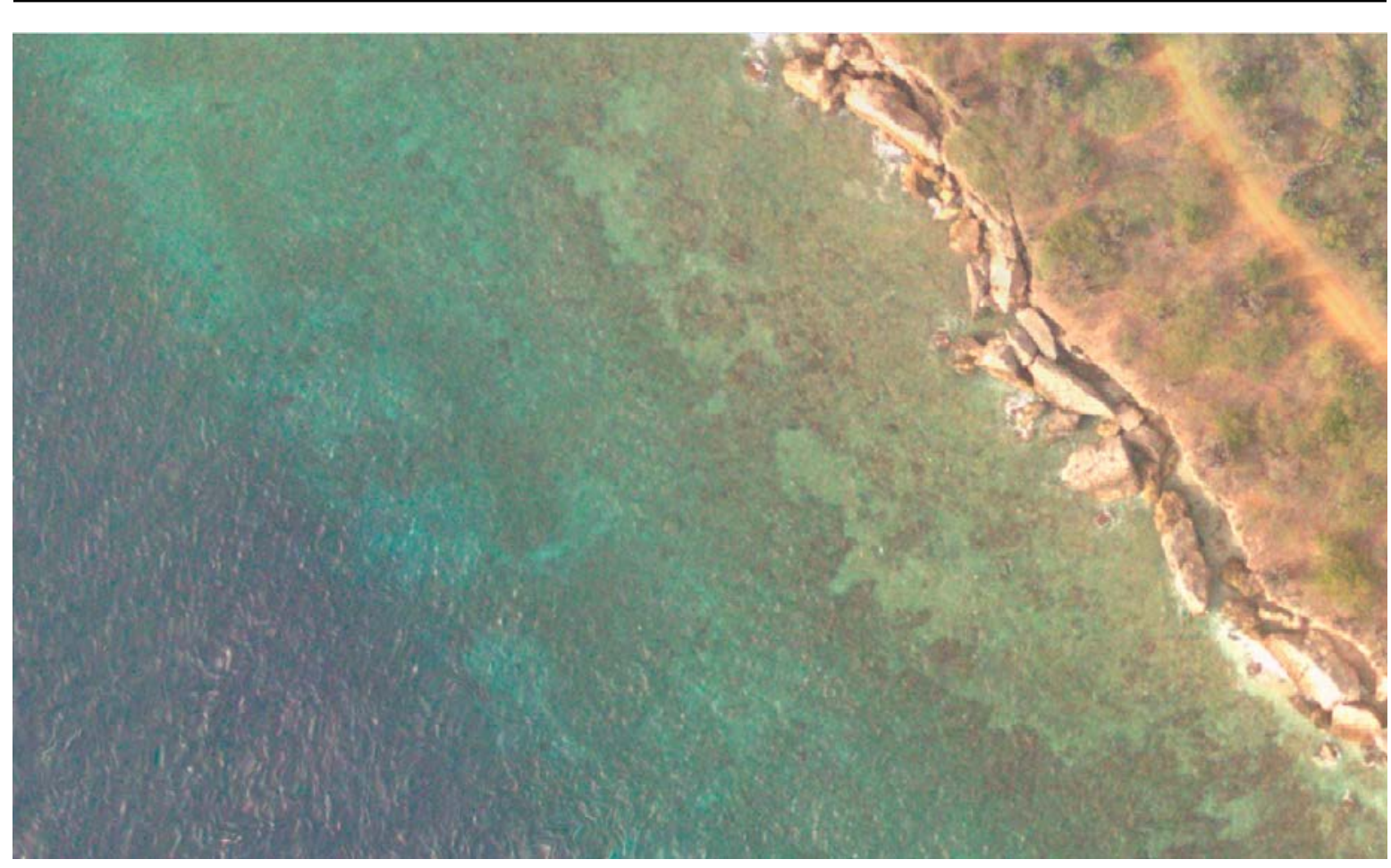

Figure 7. Example of the RGB orthophoto at full resolution of $15 \mathrm{~cm}$ pixels.

Due to these distortions, it was necessary to perform additional manual geo-rectification steps. The additional georectification was performed in ARCGIS with the Georeferencing Tool (Figure 8) and using the ARCGIS online georeferenced basemap (World Imagery Source: Esri, DigitalGlobe, GeoEye, Earthstar Geographics, CNES/Airbus DS, USDA, USGS, AEX, Getmapping, Aerogrid, IGN, IGP, swisstopo, and the GIS User Community), which looks like google maps. Identical locations were identified on the ortho-mosaic as well as on the ARCGIS basemap, along with the entire coast of Bonaire. The final transformation of the ortho-mosaic was performed as first order polynomial with an RMS error of $0.45 \mathrm{~m}$. The output spatial resolution of the RGB orthomosaic was set to 1-meter resolution using the Transverse WGS_1984_UTM_Zone_19N.

In a next step, the RGB ortho-mosaic was used as the basemap for the georecftification of the 5 hyperspectral mosaics (B1, B2, B3, B4 and $\mathrm{B} 5$, see also Figure 2). Also in this stage a first order polynomial transformation was performed with an RMS error of approximately 0.58 .

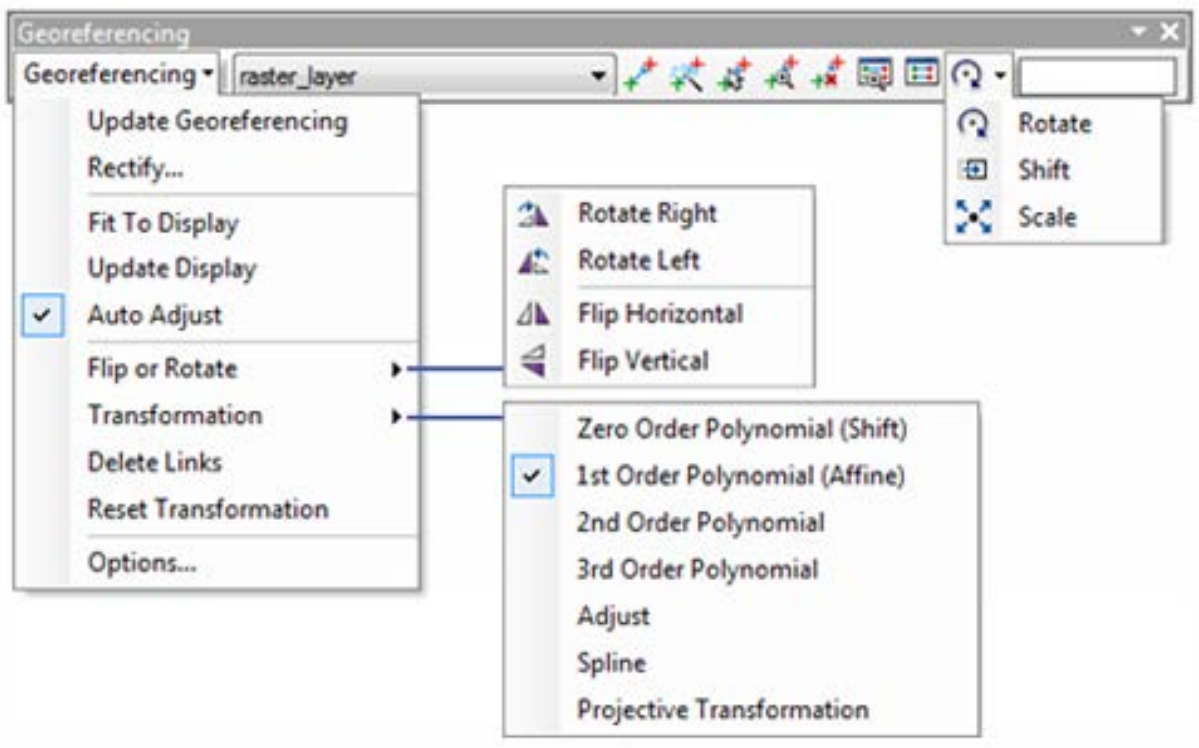

Figure 8. The ARCGIS georeferencing tool 


\subsection{Water column corrections}

This section concerns the further processing of the hyperspectral imagery from at-ground-level reflectance factors to seafloor reflectance factors to enable a better classification of the coral reef system. The section starts with a general introduction followed by the theory, the used water depth data (bathymetric model), the deep water spectrum and the final seafloor hyperspectral reflectance data.

When light penetrates water its intensity decreases exponentially (attenuates) with increasing depth because of two processes, absorption and scattering (Figure 9). The degree of attenuation differs with the wavelength of the electromagnetic radiation. In the region of visible light, the red part of the spectrum attenuates more rapidly than the shorter-wavelength blue part (Nieto, 2013; Mumby et al., 2004).
Absorption is wavelength-dependent and involves the conversion of electromagnetic energy into other forms such as heat or chemical energy. In clear waters of Bonaire, the main absorber is the water itself, which strongly absorbs red light and has a smaller effect on shorter wavelength blue light. Also on the minor scale the algae, particulate matter in suspension, and dissolved organic compounds affect the absorptions. Scattering is when the electromagnetic radiation interacts with suspended particles in the water column and changes direction. This process increases with the suspended sediment load of the water, so in more turbid waters more scattering occurs. The spectra of a benthic habitat thus change with increasing depth. As depth increases, the separability of habitat spectra declines, as shown in Figure 10 with the example of seagrass.

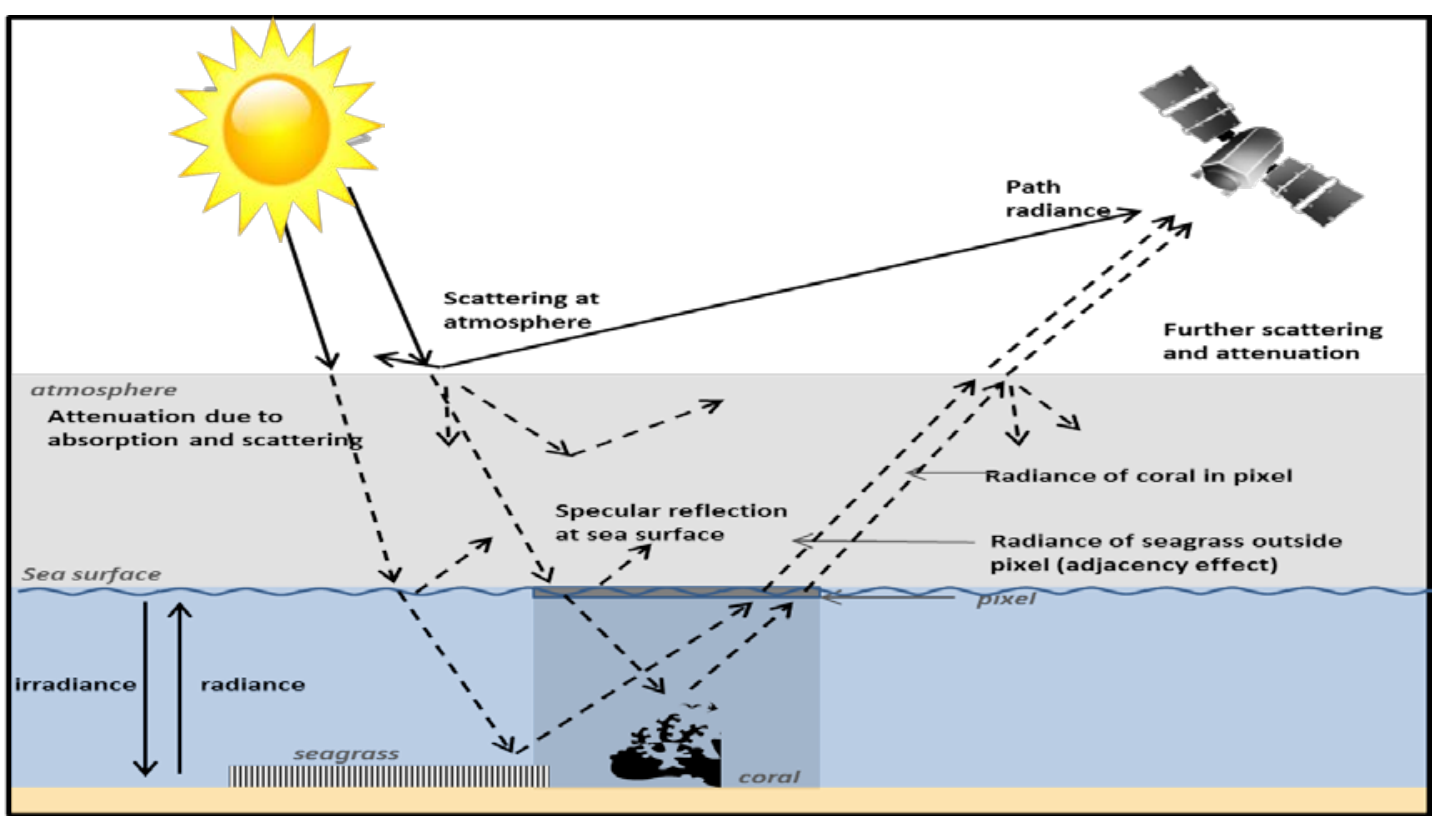

Figure 9. Factors influencing the amount of radiance reaching the sensor over a water mass (own elaboration based on Edwards (1999).

Figure 10 also shows how the spectra of the same stratum at a depth of $5 \mathrm{~m}$, for example, will be very different to that at $15 \mathrm{~m}$. Similarly, the spectral signature of one substrate at one depth could be very similar to the profile of another stratum at a different depth. The spectral radiances are therefore influenced both by the reflectance of the substrata and by depth (as well as by scattering by the sediment load of the water), and will create confusion when attempting to use visual inspection or multispectral classification to map habitats. Therefore, for benthic habitat mapping it is important to remove the influence of water depth. Camera capabilities are also important. The used hyperspectral camera measures from $450 \mathrm{~nm}$ to $950 \mathrm{~nm}$. And as can been seen in the figure below, mainly bands in the violet-bluecyan till green range (Band $1=450.0 \mathrm{~nm}$ to Band $15=520.0 \mathrm{~nm}$ ) are useful for measurements at deeper depths to a maximum of $20-30 \mathrm{~m}$ depth. 


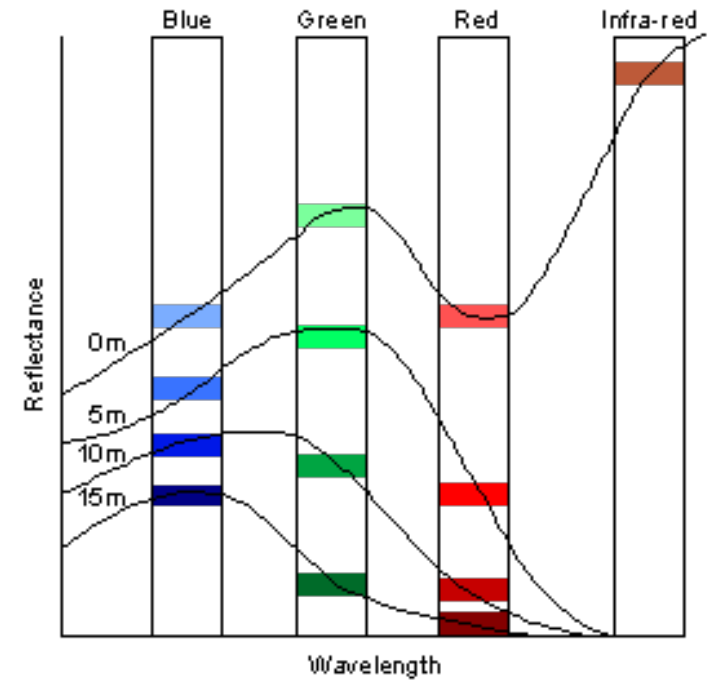

Figure 10. Spectra for a benthic habitat, in this case seagrass (Green et al., 2000).

\subsubsection{Theory ${ }^{1}$}

The original HYMSY data we have calibrated to be at-ground-reflectance factor units following the definition:

$$
R=\pi \frac{L_{\text {target }}}{E_{\text {target }}}
$$

Where $L_{\text {target }}$ is the radiance reflected from the target and $E_{\text {target }}$ is the irradiance originally illuminating the target. In practice it is impossible to retrieve irradiance information for every pixel in the imagery separately. Thus it is usually practical to assume a constant irradiance over the whole imaged area.

With HYMSY data the irradiance in the scene has been defined using a reference panel method:

$$
E=\frac{L_{\text {reference }}}{\pi R_{\text {reference }}}
$$

Using this irradiance, the reflectance factor equation becomes:

$$
R=\frac{L_{\text {target }}}{L_{\text {reference }}} R_{\text {reference }}
$$

Where $L_{\text {reference }}$ is the radiance reflected from the reference target (grey concrete dock in the city) and $R_{\text {reference }}$ is the reflectance factor of the reference target. This method assumes that:

- the target is illuminated the same way as the reference target, and

- the radiance detected by the sensor equals the radiance that left the target
As found in literature, there are various techniques to correct for depth. Nevertheless, the removal of the influence of depth on bottom reflectance would require two main variables, a measurement of depth for every pixel, and a knowledge of the attenuation characteristics of the water column (e.g. concentrations of dissolved organic matter). As these two variables are difficult to obtain in most areas, Lyzenga (1981) proposed a simple image-based approach to compensate for the effect of variable depth when mapping bottom features (water column correction). This method was then expanded by Mumby et al. (1998).

The main idea of this water column correction method is that instead of predicting the reflectance of the seabed, the method produces a 'depth-invariant bottom index' from each pair of spectral bands. This method is only truly applicable to clear waters. However, where water properties are moderately constant across an image, the method strongly improves the visual interpretation of imagery and should improve classification accuracies (Green et al., 2000).
These assumptions are decently valid for all targets on dry ground (atmospheric correction ignored) but with underwater targets both assumptions are compromised.

The first disturbing effect is transmittance $(T)$ through the water body. Both the down-welling irradiance and upwelling radiance reflected from target get weakened by absorption of water:

$$
E_{\text {seafloor }}=T(d) E_{\text {surface }}
$$

$$
L_{\text {surface }}=T(d) L_{\text {seafloor }}
$$

Where $d$ is the water depth (length of average optical path).

In addition to this water transmittance, the observed radiance reading also includes a glare ( $\left.L_{\text {glare }}\right)$ component from water surface. Thus the total detected radiance is:

$$
L_{\text {observed }}=L_{\text {glare }}+T(d, \lambda) L_{\text {seafloor }}
$$

In these terms, the reflectance factor equation for remote sensing of targets on sea floor would be:

$$
R_{\text {seafloor }}=\pi \frac{L_{\text {seafloor }}}{E_{\text {seafloor }}}
$$

While, the standard HYMSY data product $\left(R_{s t d}\right)$ has been calculated as:

$$
R_{\text {std }}=\pi \frac{L_{\text {observed }}}{E_{\text {surface }}}
$$

\footnotetext{
${ }^{1}$ Following Suomalainen et al. (2014)
} 
Equation 8 can be expanded further to:

$$
\begin{gathered}
R_{\text {std }}=\pi \frac{L_{\text {glare }}+T(d, \lambda) L_{\text {seafloor }}}{E_{\text {surface }}} \\
R_{\text {std }}=\pi \frac{L_{\text {glare }}}{E_{\text {surface }}}+T(d, \lambda)^{2} \pi \frac{L_{\text {seafloor }}}{E_{\text {seafloor }}}
\end{gathered}
$$

To find the glare the following procedure was used. If we find in the imagery pixels which have $\left[T(d, \lambda)^{2} L_{\text {seafloor }}=0\right]$ the equation 10 simplifies to format:

$$
R_{\text {std,glare only }}=R_{\text {glare }}=\pi \frac{L_{\text {glare }}}{E_{\text {surface }}}
$$

This is practically the case for all deep water pixels in the imagery as with those is can be assumed that the $L_{\text {seafloor }}=0$. Thus we can retrieve $R_{\text {glare }}$ by taking the average spectrum from a group of deep water pixels.

If the equations 7 and 11 are placed in equation 10 we get:

$$
R_{\text {std }}=R_{\text {glare }}+T(d, \lambda)^{2} R_{\text {seafloor }}
$$

From this equation we can derive the basic correction equation for retrieving the seafloor reflectance factors:

$$
R_{\text {seafloor }}=\frac{R_{\text {std }}-R_{\text {glare }}}{T(d, \lambda)^{2}}
$$

Unfortunately, for a proper glare correction, the glare spectrum should be separately known for each pixel as the intensity of the glare varies with the view angle, waves, and cloud situation for every pixel separately. Thus using a simply a constant $R_{\text {glare }}$ spectrum for all pixels gives bad results. However we can get around this. In NIR bands $(>750 \mathrm{~nm})$ the water transmittance is close to zero on all relevant water depths. Thus the NIR bands on every pixel effectively contains the pure $R_{\text {glare }}$ component for that pixel. By assuming that the glare spectrum has constant spectrum shape, but varying intensity, the mean reflectance factor of each pixel in NIR $\left(R_{\text {std }}(750-850 \mathrm{~nm})\right)$ can be used to scale the standard deep water glare spectrum shape $\left(R_{\text {glare }}\right)$ to intensity level correct for that pixel.. Thus the final practical equation for retrieving seafloor reflectance factor is:

$$
\begin{aligned}
& R_{\text {seafloor }}(\lambda) \\
& =\frac{R_{\text {std }}(\lambda)-R_{\text {glare }}(\lambda) \frac{R_{\text {std }}(750-850 \mathrm{~nm})}{R_{\text {glare }}(750-850 \mathrm{~nm})}}{T(d, \lambda)^{2}}
\end{aligned}
$$

Where

- $R_{\text {std }}$ is the uncorrected reflectance factor spectrum of the pixel from standard HYMSY processing,

- $R_{\text {glare }}$ is the average glare spectrum shape acquired from some deep water pixels, and

- $T$ is the one-way transmittance of water with depth $d$

\subsubsection{Water column depth data}

The first requirement for water transmittance correction is to have the water depth at every pixel. So what is needed is a bathymetric model with a 1-meter spatial resolution $(x, y, z)$ of the coastal zone of Bonaire. But unfortunately no such bathymetric model was available or foreseen on a short term. What was available, was the ASTER DEM with a 30-meter spatial resolution for only the terrestrial part of the globe, including Bonaire. Additional sea point depth measurements were made by Erik Meesters and students at specific locations. Below we describe the method that has been used to derive a bathymetric model of Bonaire's coastal shore based on the interpolation of the ASTER DEM through points measured at sea with the specific sea depth.

\subsubsection{ASTER GDEM}

ASTER GDEM (Global Digital Elevation Model) has been produced as a joint activity of the Ministry of Economy, Trade, and Industry
(METI) of Japan and the United States National Aeronautics and Space Administration (NASA). The ASTER (Advanced Spaceborne Thermal Emission and Reflection Radiometer) instrument was built by METI and launched onboard NASA's Terra spacecraft in December 1999. It has an along-track stereoscopic capability using its near-infrared spectral band and its nadir-viewing and backward-viewing telescopes to acquire stereo image data with a base-to-height ratio of 0.6. The ASTER GDEM covers land surfaces between $83^{\circ} \mathrm{N}$ and $83^{\circ} \mathrm{S}$ and is comprised of $22,6001^{\circ}$ by $1^{\circ}$ tiles. Tiles that contain at least $0.01 \%$ land included. The ASTER GDEM is in GeoTIFF format with geographic lat /long coordinates and a 1 arcsecond (approximately $30 \mathrm{~m}$ ) grid. It is referenced to the WGS84/EGM96 geoid. Preproduction estimated (but not guaranteed) accuracies for this global product were $20 \mathrm{~m}$ at $95 \%$ confidence for vertical data and $30 \mathrm{~m}$ at $95 \%$ confidence for horizontal data (https://asterweb.jpl.nasa.gov/gdem.asp). The ASTER DEM for Bonaire is shown in Figure 11. 


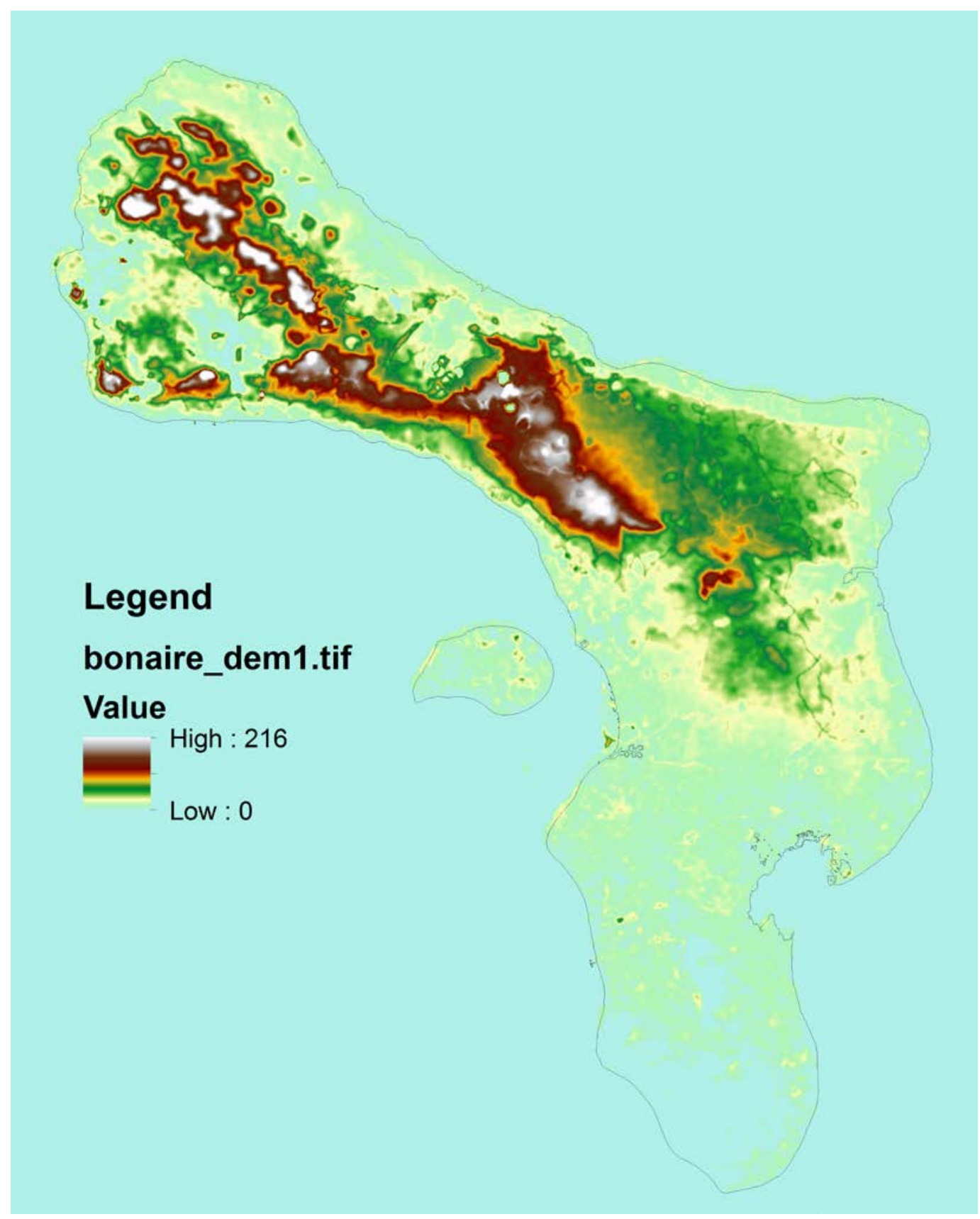

Figure 11. Detail of AsterDEM for Bonaire with a 30-meter spatial resolution and 1m height resolution (Source: NASA)

\subsubsection{Processing bathymetric model}

The core ARCGIS script that has been used is "Topo to Raster" (Spatial Analyst). The script interpolates a correct raster surface from point, line, and polygon data. The interpolation procedure has been designed to take advantage of the types of input data commonly available and the known characteristics of elevation surfaces. This method uses an iterative finite difference interpolation technique. It is optimized to have the computational efficiency of local interpolation methods, such as inverse distance weighted (IDW) interpolation, without losing the surface continuity of global interpolation methods, such as Kriging and Spline. It is essentially a discretized thin plate spline technique (Wahba, 1990) for which the roughness penalty has been modified to allow the fitted DEM to follow abrupt changes in terrain, such as streams, ridges and cliffs.

Therefore the ASTERDEM was converted to contour lines, and to improve the calculations extra height points were added for the lowlands of Bonaire, as well as extra measured sea depth points that were collected in a separate campaign (Figure 12). 


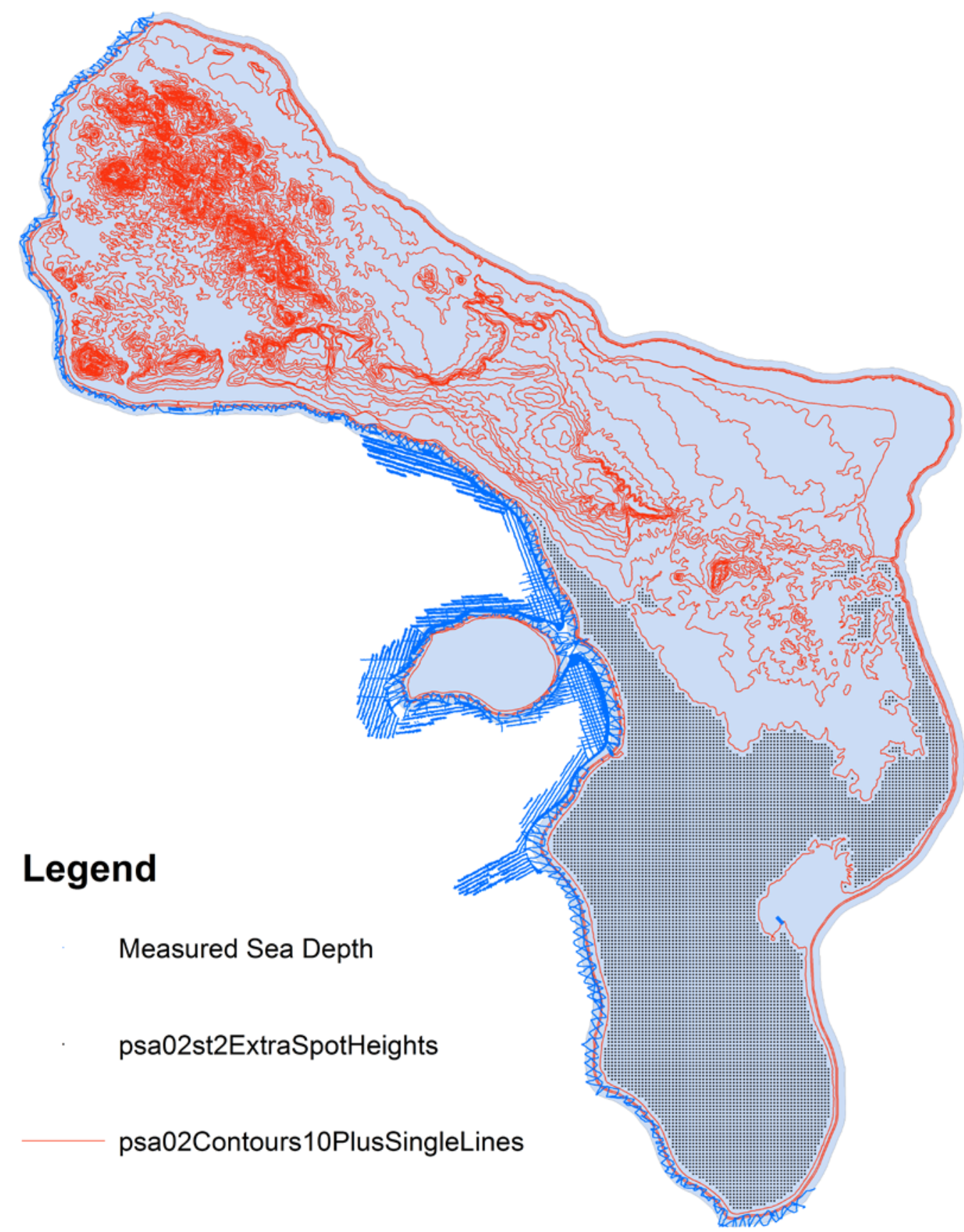

Figure 12. Input points and line features used as an input for Topo to Raster (Spatial Analyst) script of ARCGIS to create the bathymetric model

A detail of the extrapolated DEM into the sea is given below in Figure 13. Extrapolation into the sea has been performed till 300 meters from the shoreline. Finally, only that part in the sea has been used that was covered by the hyperspectral data (right part of Figure 13). This modelled bathymetric model has a spatial resolution of 1 meter with modelled sea depth in meters.

Please note that the final modelled bathymetric model is something completely different than a bathymetric survey. A bathymetric survey would provide much more accurate data, and would preferably show the micro-relief of the coral reef. Our bathymetric model does not show this micro-relief of the coral reef, and is only an approximation of the water column depth. So in fact, the final bathymetric model is still seen as inaccurate, but was used as the best choice for the current situation for the water column correction of the hyperspectral datacube to enable the calculation of a seafloor surface reflectance. When better bathymetric data become available (e.g. from the Royal Hydrographic Survey) the reflectance at seafloor calculations may be improved. 


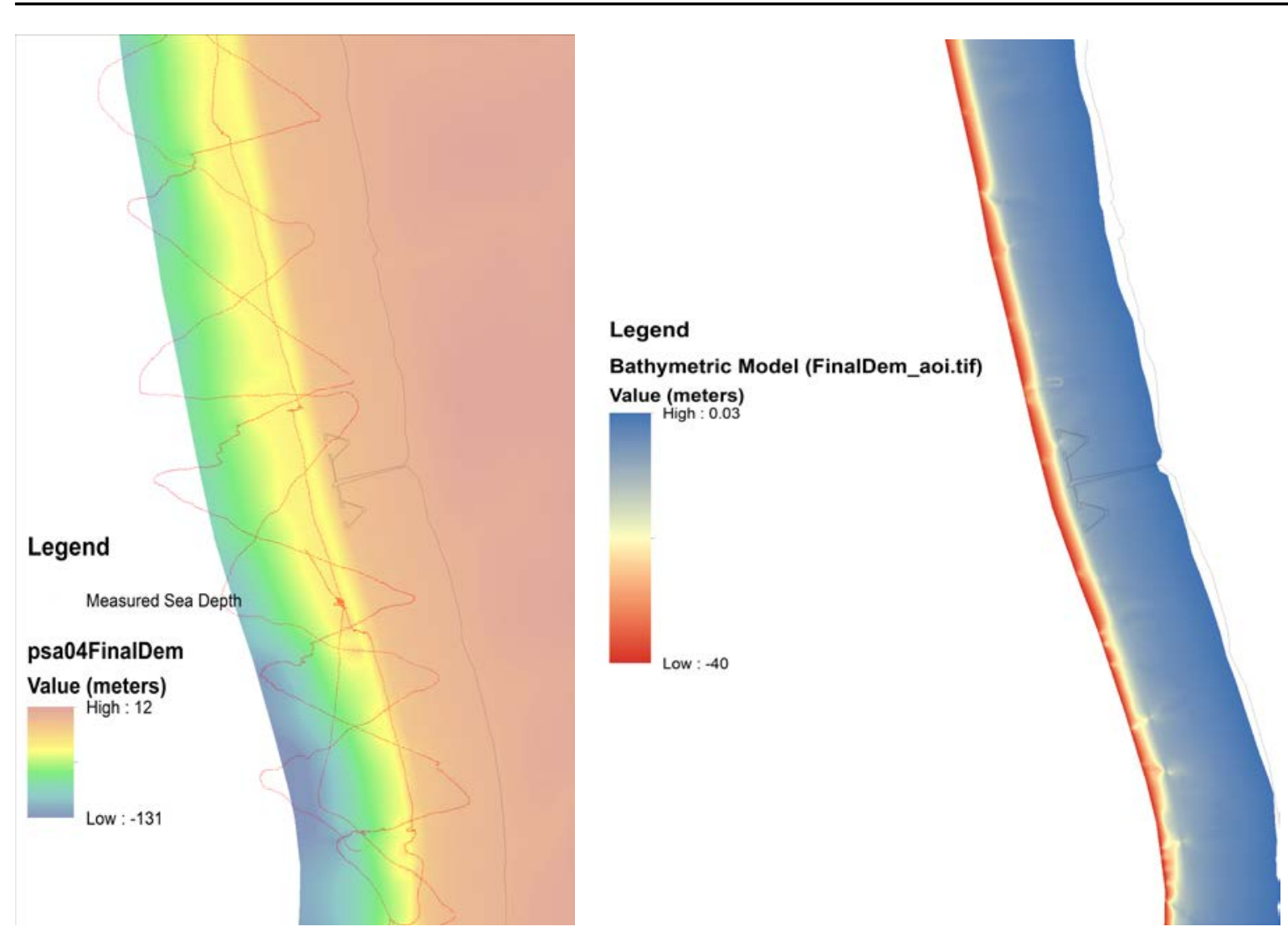

Figure 13. Left detail of the final extrapolated height model into the sea till 300 meters from the coastline overlaid with the measured sea depth points (red dotted lines). Right detail of the modelled bathymetric model being covered by the hyperspectral datacube. The bathymetric model has a spatial resolution of $1 \mathrm{~m}(\mathrm{x}, \mathrm{y}, \mathrm{z})$

\subsubsection{Glare/ deep water spectrum}

Next the glare of water surface needed to be removed from the data using equation 14. To estimate the surface glare component on the spectra, we averaged the spectra of some pixels with deep water that contained practically no sea bottom reflectance component (Figure 14).
To sample the pixels we selected in Klein Bonaire image

('B1_Datacube_georect16bit_aoi.tif') the TIFF tile number $5 \overline{9} 6$ (as one-based indices) and selected the pixels which had more than $30 \mathrm{~m}$ of water depth. The resulting average spectrum is shown in Figure 15.
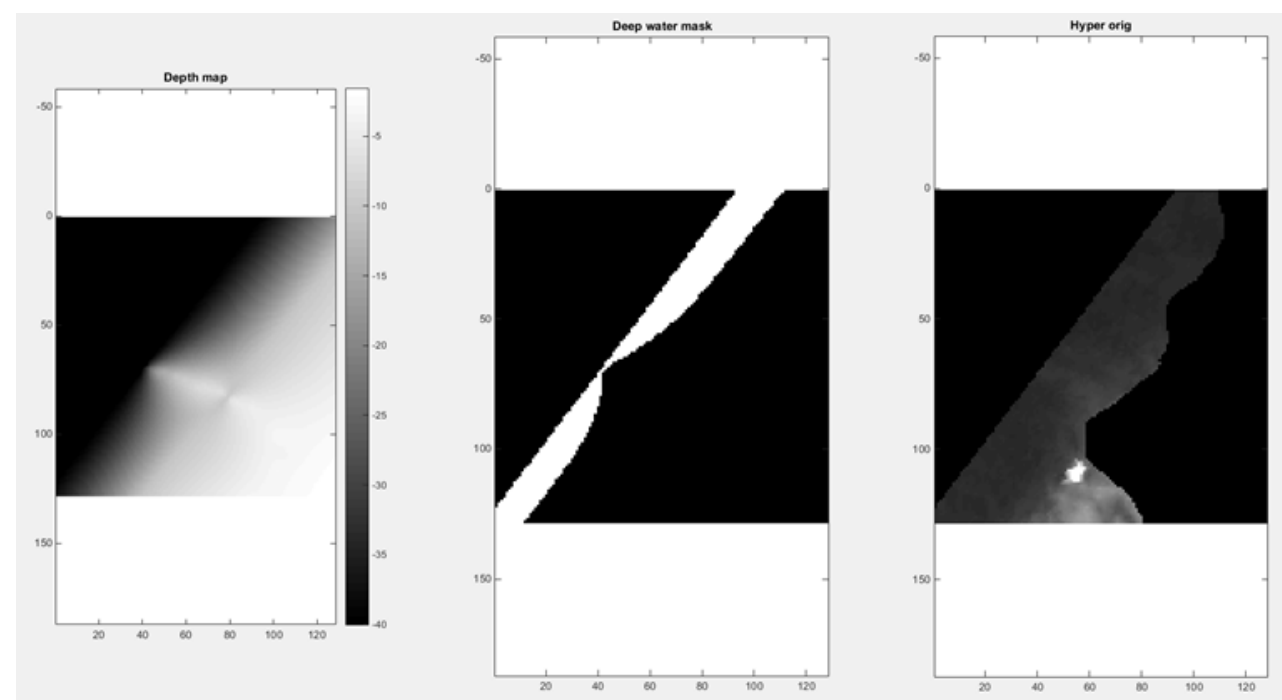

Figure 14. Sampling of deep water pixels to estimate the glare of water surface. 


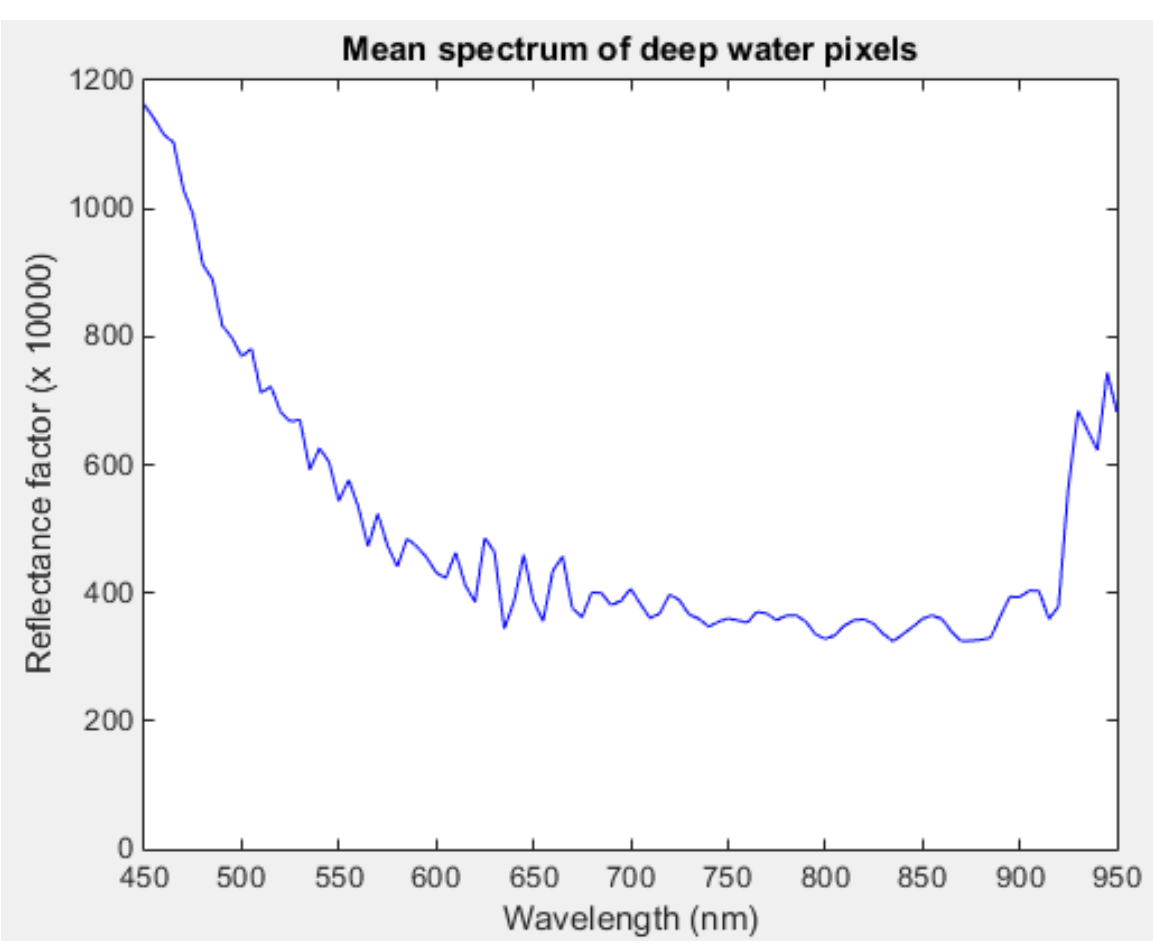

Figure 15. Spectrum of deep water pixels. This spectrum was used to correct for the water surface glare present in all observations. The reflectance factor is expressed with a factor $\times 10,000$.

\subsubsection{Water transmittance}

We developed a Matlab function WaterTransmittance.m which calculates water transmittance for given water thickness and wavelength/spectrum using Beer-Lambert law and water optical data of (Hale and Querry, 1973). This function and the water depth data was used to calculate the water transmittance separately for every hyperspectral pixel in our data (Figure 16). While doing this, we found that the used Bonaire water depth model underestimates the water level. This might have been due to high tide during the mapping flight or some other unknown calibration issue. This effect was visible especially in shallow water pixels where visual assessment of the corrected spectra did not show strong enough correction. To empirically correct for this effect, the model water depth was incremented by $1 \mathrm{~m}$ for all transmittance calculations. This appeared to fix the under correction in shallow parts.

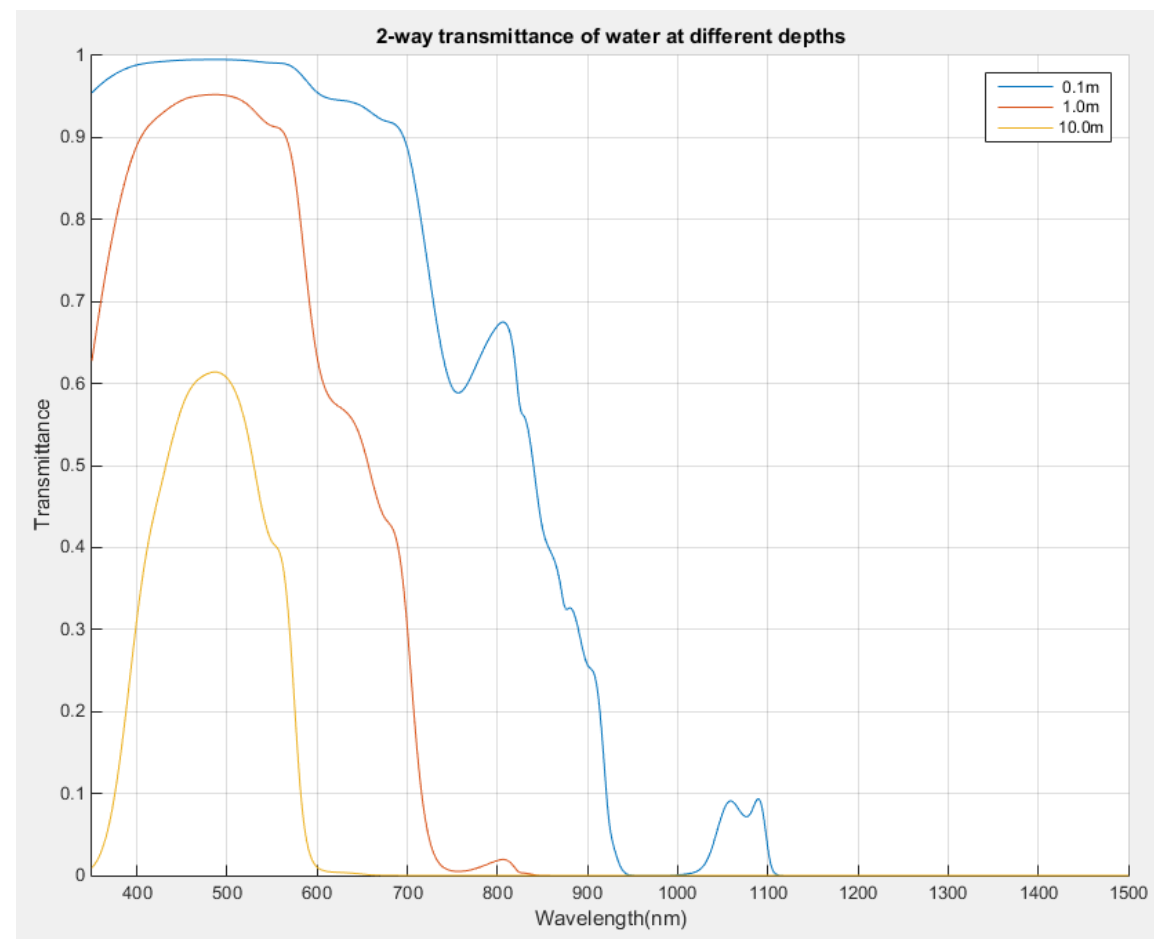

Figure 16. Examples of calculated two-way transmittance spectrum of water when observing targets on different depths. 


\subsubsection{Seafloor reflectance}

Using the methodologies described in above chapters, the effects of water surface reflectance and water transmittance were removed from the standard HYMSY abovewater-reflectance-data, and seafloor reflectance maps were produced.

In the processing of the data we filtered away all pixels and wavelengths that had a 2-way transmittance of less than $15 \%$. For these pixels there was not enough signal to provide any reliable data. With 15\% transmittance the water transmittance correction amplifies the noise and errors from calibration uncertainty approximately 6 times $(1 / 0.15=\sim 6)$. Thus the signal we get from such depths gets totally lost in the noise and errors in glare correction, rendering those pixels and wavelengths useless.

The filtered pixels/wavelengths in the corrected data cube were marked with a no-data-value (no data value 65535).
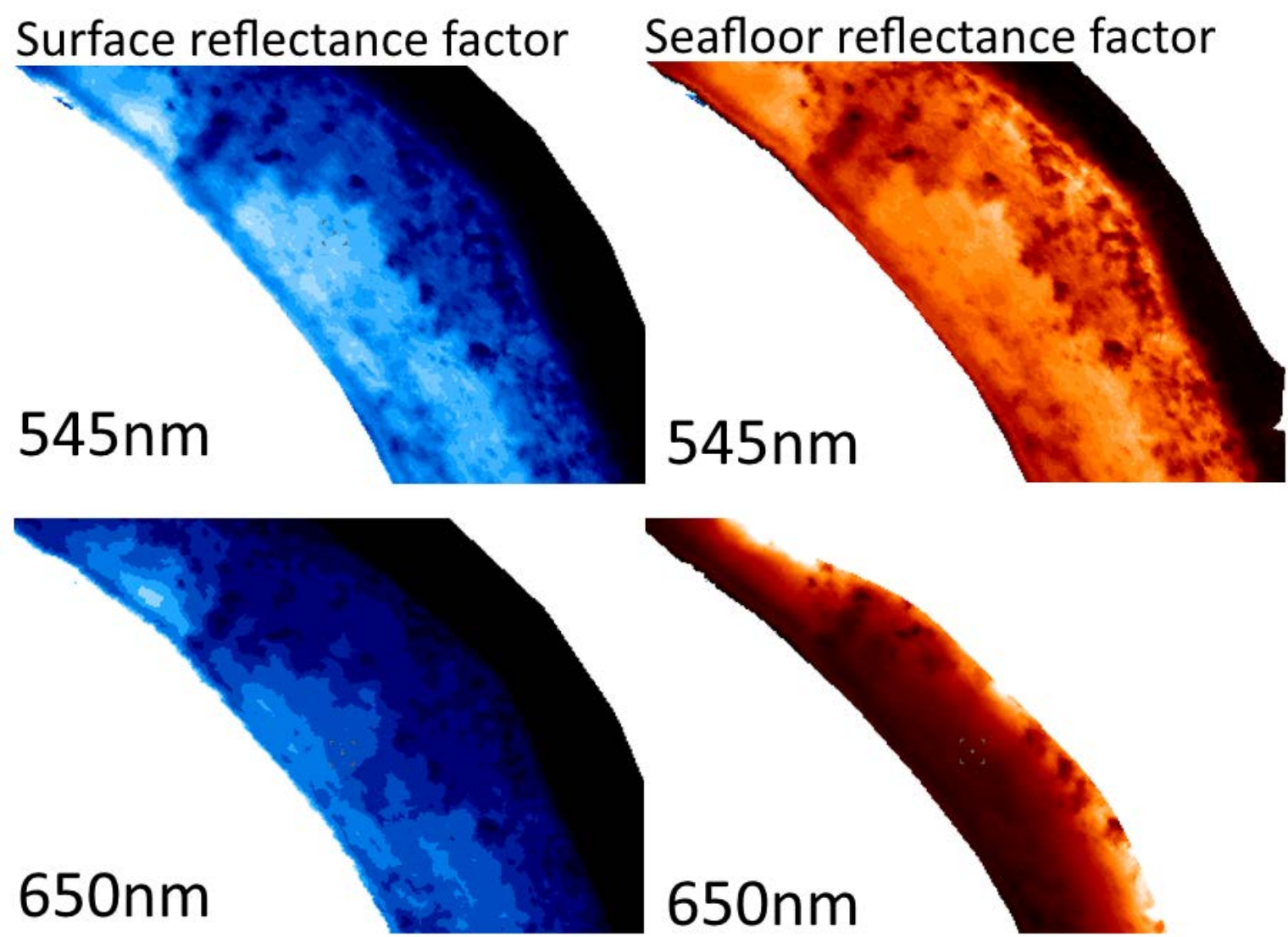

Figure 17. The original standard HYMSY reflectance factor maps (left column) and the corrected seafloor reflectance factor maps (right column) at 545nm (green) and 650nm (red).

The result of all the corrections are shown in Figure 17 with on the left side the uncorrected image and on the right side the improved image after all the corrections have been applied. Note how the bright sand is showing similarly in the

\subsubsection{Selection of spectral bands for coral reef classification}

As indicated in Figure 18, many spectral bands have no sea surface reflectance values after a few meters depth, especially beyond $600 \mathrm{~nm}$. These spectral bands have much more no-datavalues (value $=65535$ ) than in the blue-green region. So in principle we would only select spectral bands in the blue part of the electromagnetic spectrum that has a maximum penetration of the water column. But using less spectral bands means a smaller $\mathrm{n}$-dimensional space that limits the distinction of coral reef classes. So there is a clear trade-off between the maximum number of bands and the depth that can be reached to distinguish the various coral corrected data no matter in what depth it is in, while in the original the signal gets darker the deeper the water is. Note also the spatial extent of the corrected data is reduced from the original and changes also with wavelength. 
corrected to sea surface reflectance values is given below in Figure 19.
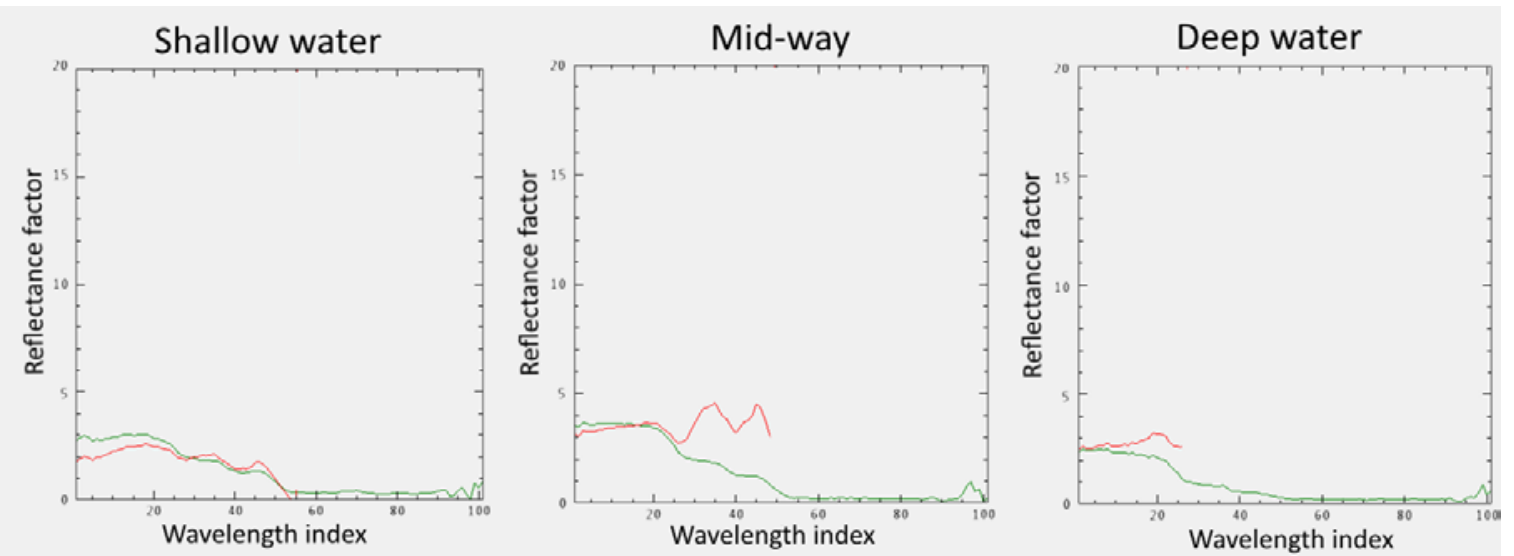

Figure 18 The surface and seafloor spectra of targets at different depths.

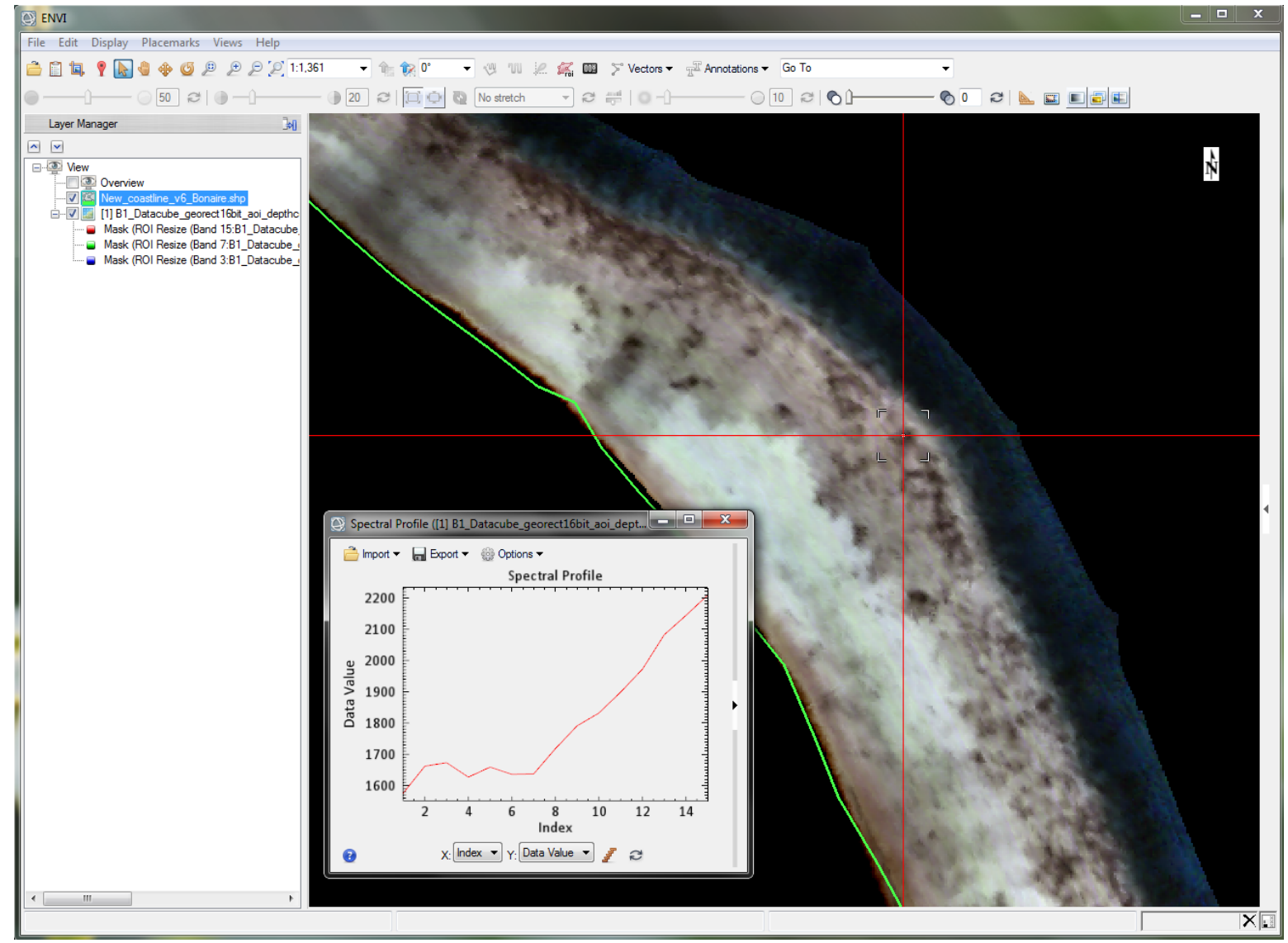

Figure 19 Hyperspectral datacube limited to the first 15 spectral bands covering the violet-blue-cyan till green range (Band $1=450.0 \mathrm{~nm}$ to Band $15=520.0 \mathrm{~nm}$ ). This provided sea surface reflectance values to a maximum depth of 30 meters for coastal Bonaire. In this example a small part of the eastern coast of Klein Bonaire is shown. 


\section{Hyperspectral Coral Reef Classification (HCRC)}

\subsection{Classification method}

For a classification of satellite imagery there are two widely accepted methods. One is called a supervised classification and the other one is called an unsupervised classification method. For a supervised classification, such as a maximum likelihood classification, you need sufficient training samples. These training samples are normally in-situ observations of all interested coral reef classes and represent these classes in homogenously covered areas with a minimum of 5 by 5 pixels. In our case it means that sufficient (normally 10 to 20 training samples for each class and well distributed over the island) homogenous areas of at least $25 \mathrm{~m}^{2}$ have to be found for each coral reef class of interest. Moreover these training samples need to be georeferenced with an accuracy of approximately $50 \mathrm{~cm}$ to enable a link with the proper pixels in the hyperspectral datacube. As one can expect it is almost impossible to meet these conditions for coral reef mapping in general. Coral reefs are complex systems and therefore it is very hard to find homogeneous areas in terms of spectral reflectance and substrate. Moreover, in-situ observations taken while diving are in most cases not very accurately geotagged. Therefore unsupervised classifications of the hyperspectral data cubes with spectral channel 1 to 15 for all 5 regions (see Figure 2) seemed to be the most appropriate. Also due to slightly different (atmospheric and environmental) conditions the five regions could not be treated in exactly the same way.

The unsupervised classification method that was selected was the ISODATA algorithm in
ENVI (Exelis Visual Information Solutions, Boulder, Colorado). ENVI describes ISODATA as an unsupervised classification that calculates class means evenly distributed in the data space then iteratively clusters the remaining pixels using minimum distance techniques. Each iteration recalculates means and reclassifies pixels with respect to the new means. Iterative class splitting, merging, and deleting is done based on input threshold parameters. All pixels are classified into the nearest class unless a standard deviation or distance threshold is specified, in which case some pixels may be unclassified if they do not meet the selected criteria. This process continues until the number of pixels in each class changes by less than the selected pixel change threshold or the maximum number of iterations is reached.

For each ISODATA classification we selected a minimum of 10 , and a maximum of 15 classes and 10 iterations and a minimum number of 1000 pixels per class. The change percentage threshold was kept at the default value of $5 \%$. This resulted in a minimum of 13 and a maximum of 15 spectral classes for all five regions. Once having the spectral classes the difficult part started: how to label these spectral classes and mosaic the five regions seamlessly.

To enable the labelling of the spectral classes an intensive diving campaign was performed by Erik Meesters and Sander Mücher in the period from $22^{\text {nd }}$ to $30^{\text {th }}$ of June 2016 . In the next section this diving campaign is described in detail accompanied with the labelled clusters.

\subsection{Benthic habitat types}

A habitat classification scheme allows grouping of habitat types based on common ecological or geomorphological characteristics. A habitat is a type of underwater terrain where particular species are likely to be found. And of course, there is a wide variety of marine benthic habitat characterization schemes around the world. But here, considering the initial knowledge of the area, the previous fieldwork activities and the expected distinguishable characteristics in the images, a classification scheme was created by clearly identifying and defining discrete habitat classes:

1- Unconsolidated Sediment 1.1 Sand

2- Coral Reef \& Hard bottom

2.1 Pavement

2.1 Rubble

2.2 Coral reef and gorgonian

\section{3- Seagrass and algae}

3.1 Seagrass and algae

3.2 Sargassum $\mathrm{sp}$.

In principle six different coral reef classes were targeted, but not all were assigned within the study area. Five major coral reef classes are described in short below. The final typology consisted of more classes due to combinations of these five classes, and included also combinations of living and dead coral. Seagrasses and sargussum fields are important categories that are missed. The first category, sea grass, occurring in large fields on the east coast in Lac Bay were not covered by the hyperspectral campaign. Additionally, within the covered areas these classes were too fragmented to be identified.

The figure below presents a simplified scheme of benthic habitats that can be encountered in a transect perpendicular from the coast on Bonaire. 


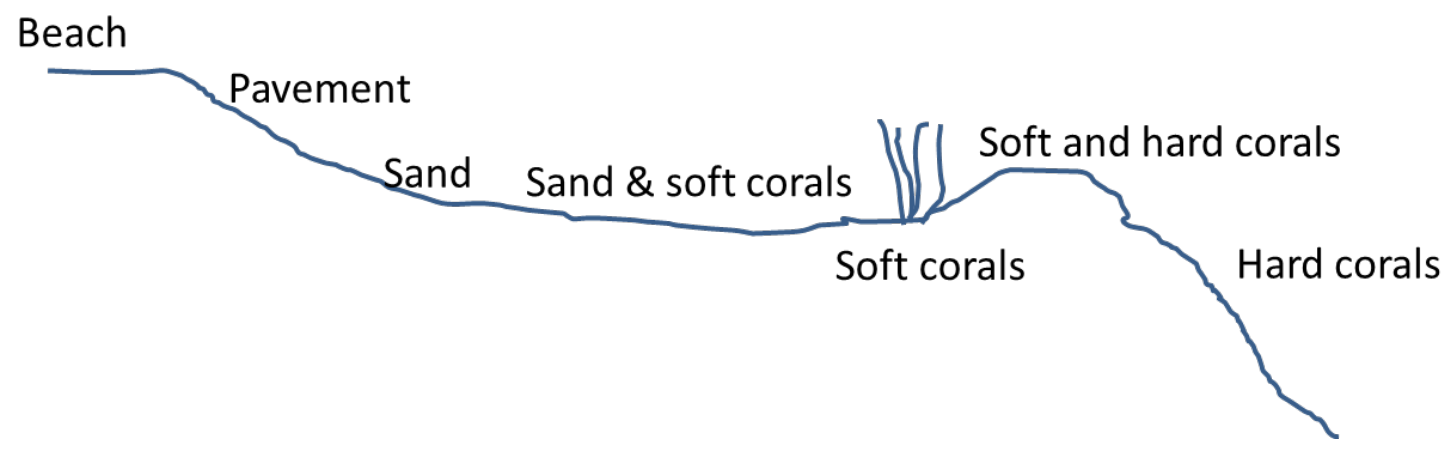

Figure 20 Schematic transect with expected benthic habitats perpendicular to the west coast of Bonaire.

\subsubsection{Pavement or hard bottom}

Hard bottoms were usually represented by smooth calcareous embankments, also called beach rock. Most frequently it occurs along the shore in shallow water less than $1 \mathrm{~m}$ deep. Corals are virtually absent from the hard bottoms with exception of small encrusting specimens and some gorgonian corals (van Duyl, 1985).

\subsubsection{Rubble}

Rubble habitat is quite diverse in terms of cover percentage and species composition. This

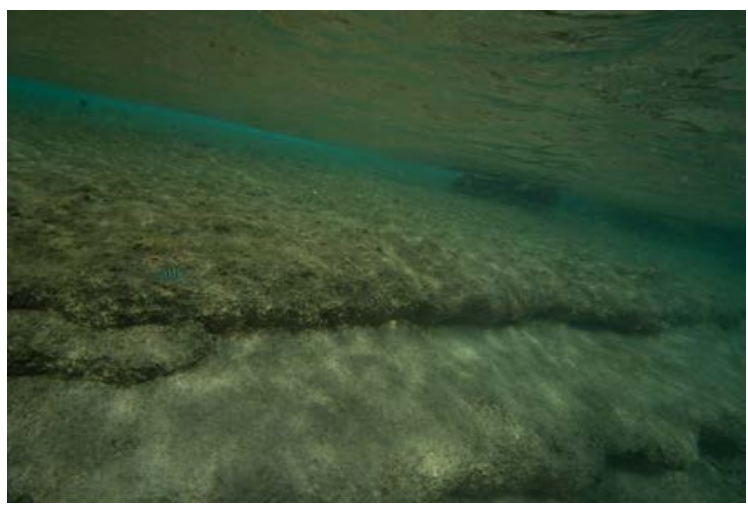

bottom type comprises of several textural and structural components, viz. loose and cemented coral debris (rubble), hard bottoms, dead reef flats and stands of dead staghorn coral (Acropora cervicornis), sometimes with (often dead) Elkhorn (Acropora palmata) and head corals in situ. All these components may be encrusted. It consists mainly of dead coral fragments often colonized by macroalgae or less frequently coralline algae (van Duyl, 1985; Nieto, 2013).

Figure 21. Example of hard bottom beach rock or Figure 22. Example of rubble as a mixture with sand pavement nearby Eden Resort, Bonaire (photo 24 near Hilmar Hooker, Bonaire (photo 22 Juni 2016) Juni 2016)

\subsubsection{Sand}

This habitat consists only of sand areas with no coverage of benthic species. It is mostly found close to shore, but also between coral and gorgonian patches. Sand areas exhibit some variations in colour, with some areas appearing to have darker sands (Nieto, 2013). Sand consists predominantly of coarse calcareous sand, derived mainly from the breakdown of the primary framework of the reef. Sand production by boring and grazing organisms such as excavating sponges, parrot fishes, and the sea urchin Diadema antillarum can be considerable (van Duyl, 1985).

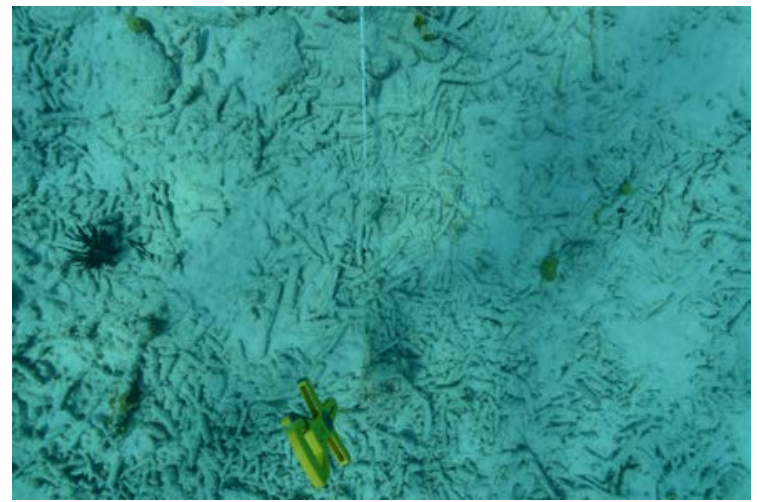

\subsubsection{Soft corals (gorgonians)}

In this group sea whip and/or sea fan cover exceeds stony coral cover. Differences between communities are based on differences in composition and proportionate cover of different species. Common sea whips involved are Pseudopterogorgia americana, P. acerosa, Plexaura flexuosa, and P. homomalla. Sea fans, which locally accompany sea whips, belong to the genus Gorgonia. 


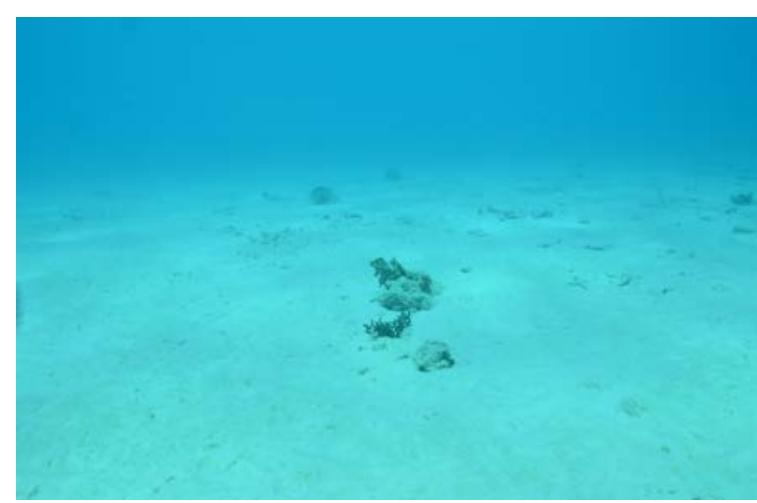

Figure 23 Example of sand near to Pink Beach, Bonaire (Photo 30 Juni 2016)

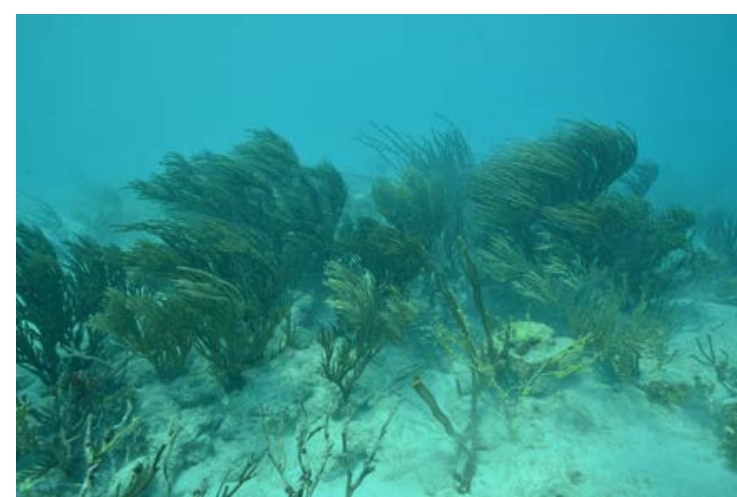

Figure 24 Example of soft corals (Gorgonians) near to Red Slaves, Bonaire (Photo 30 J uni 2016)

\subsubsection{Hard corals}

This habitat is the most species-rich and has the most diverse composition, including species of hard coral, gorgonian corals, algae and sponges. Coral communities consist of individual coral colonies (which are found in sand, rock and rubble patches) in different

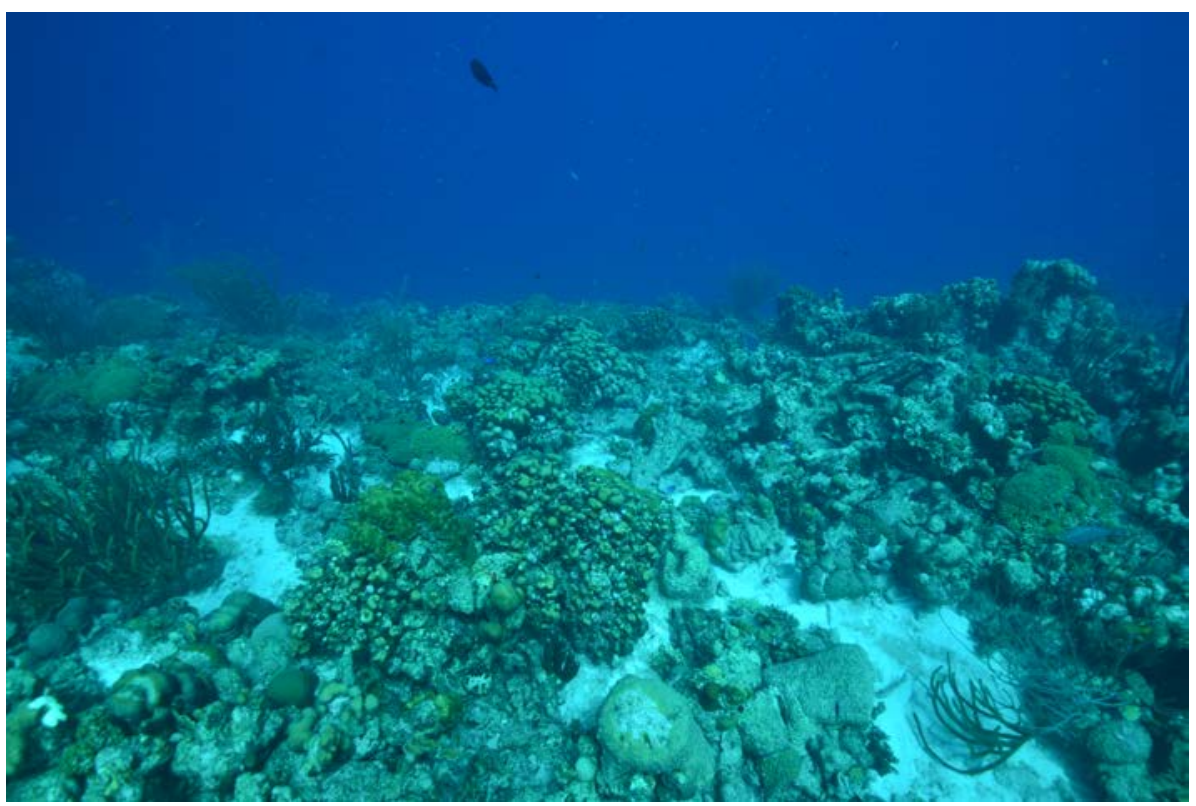

Figure 25 Example of hard corals near to Thousand Steps, Bonaire (Photo 29 Juni 2016)

\subsection{Ground-truthing}

An intensive diving campaign was performed in the period from $22^{\text {nd }}$ to $30^{\text {th }}$ of June 2016 by Erik Meesters and Sander Mücher assisted for some days by the Bonaire National Marine Park with a boat and captain Funchi and volunteer Roel van der Schoot. We were able to collect geotagged photographs in 20 transects perpendicular to the coastline across the western coast. densities, here called loose reef, intermediate reef (found in rubble and rock fields, often sand between the coral patches) and dense reef (no sandy patches between coral areas). 


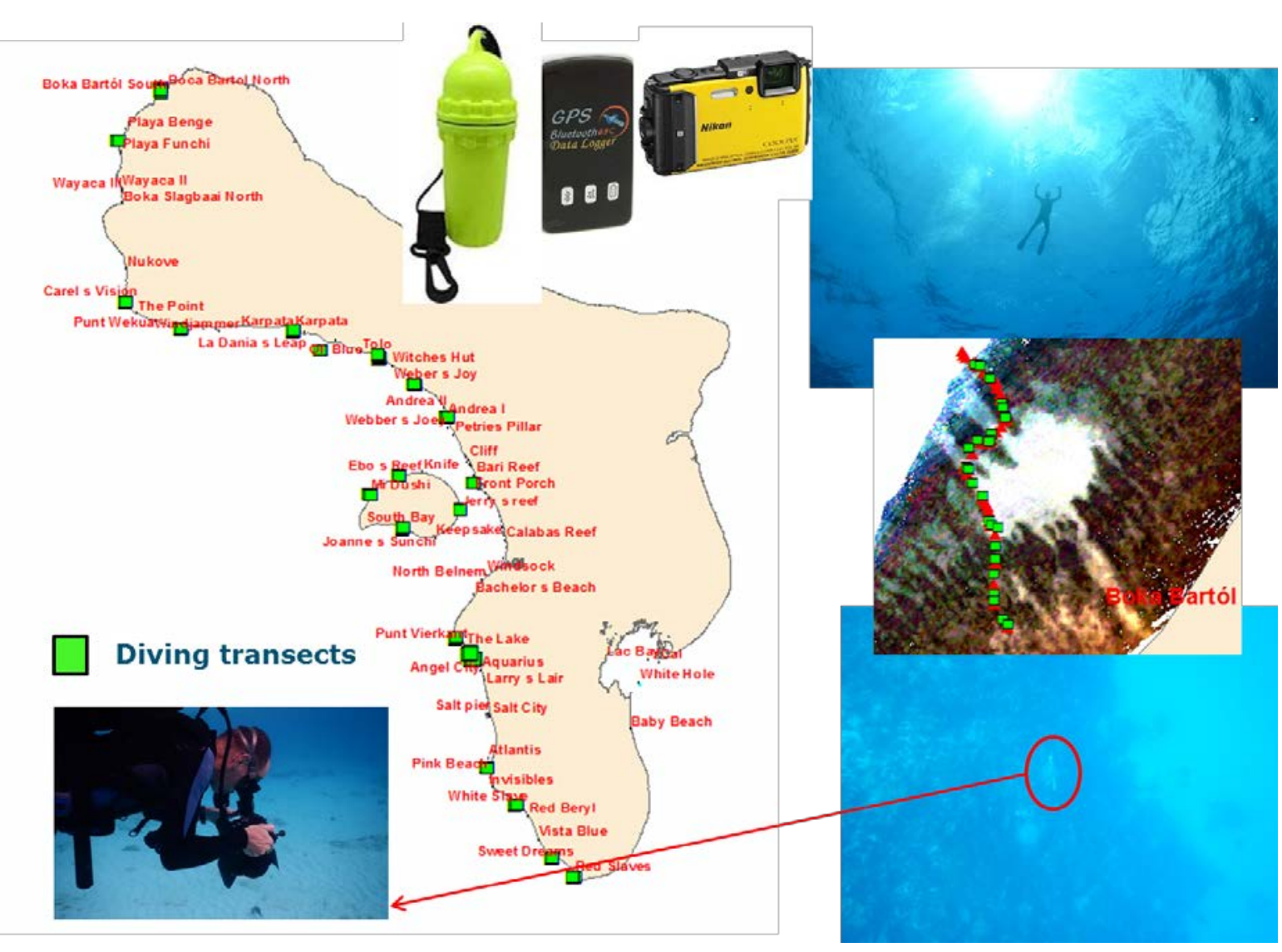

Figure 26. 20 GPS diving transects were collected in June 2016. Geotagged pictures were created by one person snorkelling at the water surface with a GPS in a plastic floating box following exactly above the divers taking pictures at the sea bottom.

\subsection{Classification result}

The final hyperspectral coral reef classification (HCRC) of Bonaire consists of 12 benthic habitat classes in a narrow strip (on average 150 meters wide) along the coast of Bonaire (approximately $50 \mathrm{~km}$ long) till a depth of approximately 20 - 30 meters. The total area covered by the HCRS is 693 ha. Note that almost the entire Eastern coast of Bonaire is missing. Main reason is that Bonaire has eastern winds causing high waves on the east coast. These waves hamper the acquisition of good hyperspectral imagery of the coral reef system along the eastern coast. Additionally, it is much more difficult to dive along the eastern coast. More extensive explanation and images of the classification process are given in the next chapter.
Table 1 provides a summary of the statistics of the HCRC. It shows clearly that the classification is dominated by a few classes: 2 'pavement, rubble, sand and corals', 4 'sand', 9 'hard corals living', with respectively, 39\%, 21\% and $15 \%$. So these 3 classes are already responsible for $75 \%$ of the coral reef.

Please note that the classification has not been validated. It means that we do not know the accuracy of each class and the overall accuracy of the classification.

The only assessment we have made are some comparisons with the Atlas of the Living Reefs from the early eighties (van Duyl, 1985) and comparison with the geotagged pictures made during the diving transects in J une 2016. 


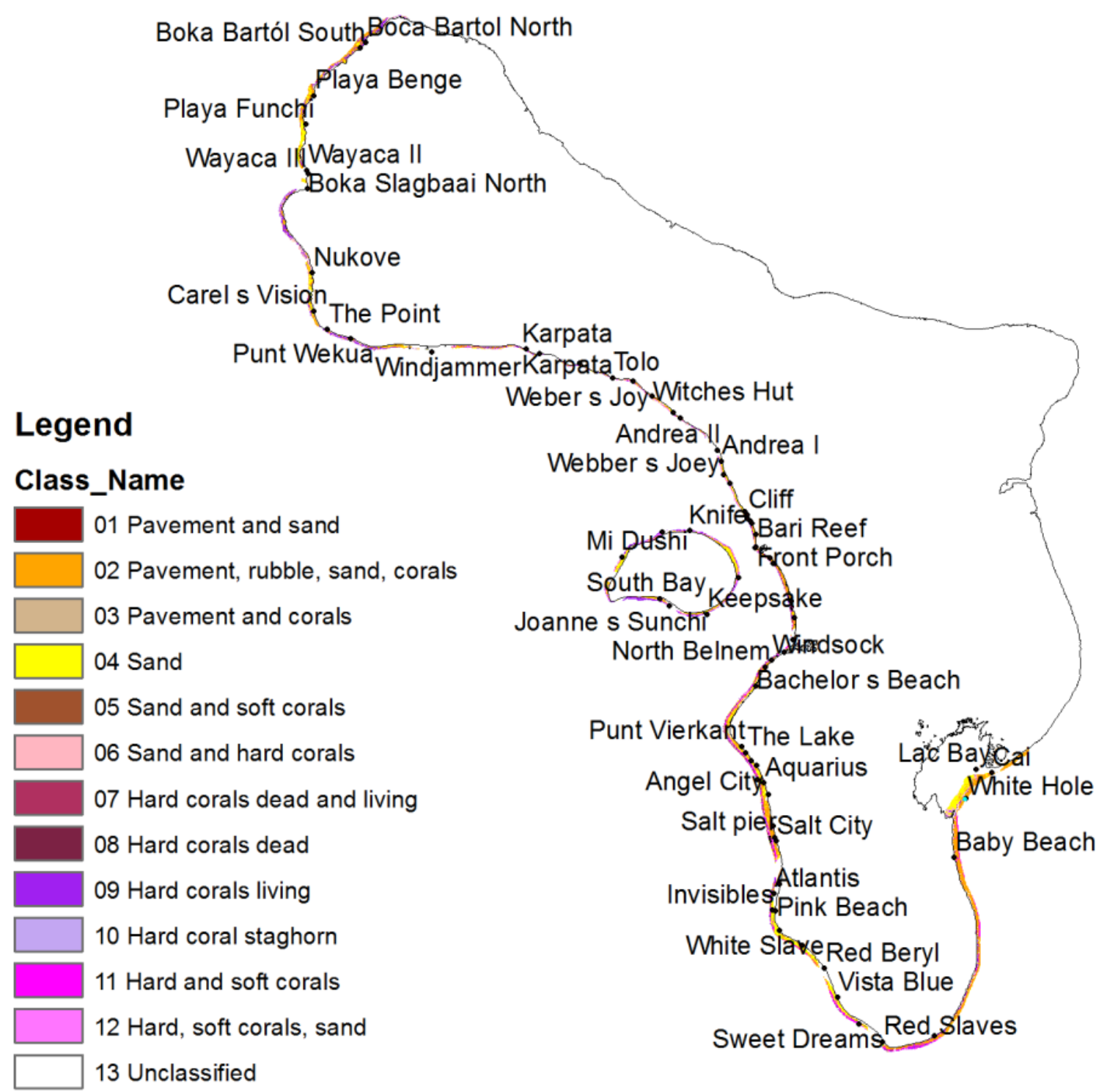

Figure 27. Overview of the final Hyperspectral Coral Reef Classification (HCRC) 
Table 1. Summary statistics of the Hyperspectral Coral Reef Classification (HCRC)

\begin{tabular}{llrr}
$\mathrm{Nr}$ & Benthic habitat class & Area (ha) & Percentage \\
1 & Pavement and sand & 1,1 & 0.2 \\
\hline 2 & Pavement, rubble, sand, corals & 270,1 & 39.0 \\
\hline 3 & Pavement and corals & 5,5 & 0.8 \\
\hline 4 & Sand & 146,4 & 21.1 \\
\hline 5 & Sand and soft corals & 1,3 & 0.2 \\
\hline 6 & Sand and hard corals & 40,1 & 5.8 \\
\hline 7 & Hard corals dead and living & 9,5 & 1.4 \\
\hline 8 & Hard corals dead & 7,0 & 1.0 \\
\hline 9 & Hard corals living & 103,1 & 14.9 \\
\hline 10 & Hard coral staghorn & 0,1 & 0.0 \\
\hline 11 & Hard and soft corals & 50,6 & 7.3 \\
\hline 12 & Hard, soft corals, sand & 57,8 & 8.3 \\
\hline & Total & $\mathbf{6 9 2 , 8}$ & $\mathbf{1 0 0 . 0}$
\end{tabular}




\subsection{Assessment of the HCRC accuracy}

Below we compare the classification by Van Duyl (1985) with the HCRC. All the examples below show that the Atlas of the Living Reefs (van Duyl, 1985) distinguishes many more coral reef categories. Many of these categories cannot be distinguished from the air and can only be identified by diving. On the other hand the 12 coral reef classes distinguished in the HCRC are already very valuable. Moreover, the Atlas of the Living Reefs of Curaçao and Bonaire (van Duyl, 1985) was made by a very intensive diving campaign over several years, while the processing and interpretation of the hyperspectral imagery did take only a few months' time. Nevertheless it is interesting to see that many boundaries drawn by van Duyl are clearly visible on the hyperspectral imagery and provides common patterns in part of the HCRC and the Atlas of the Living Reefs. Especially where it concerns sand it is clear that some of the boundaries drawn by van Duyl are not always as accurate as can be drawn from the hyperspectral imagery (unless the patch has changed in its position).

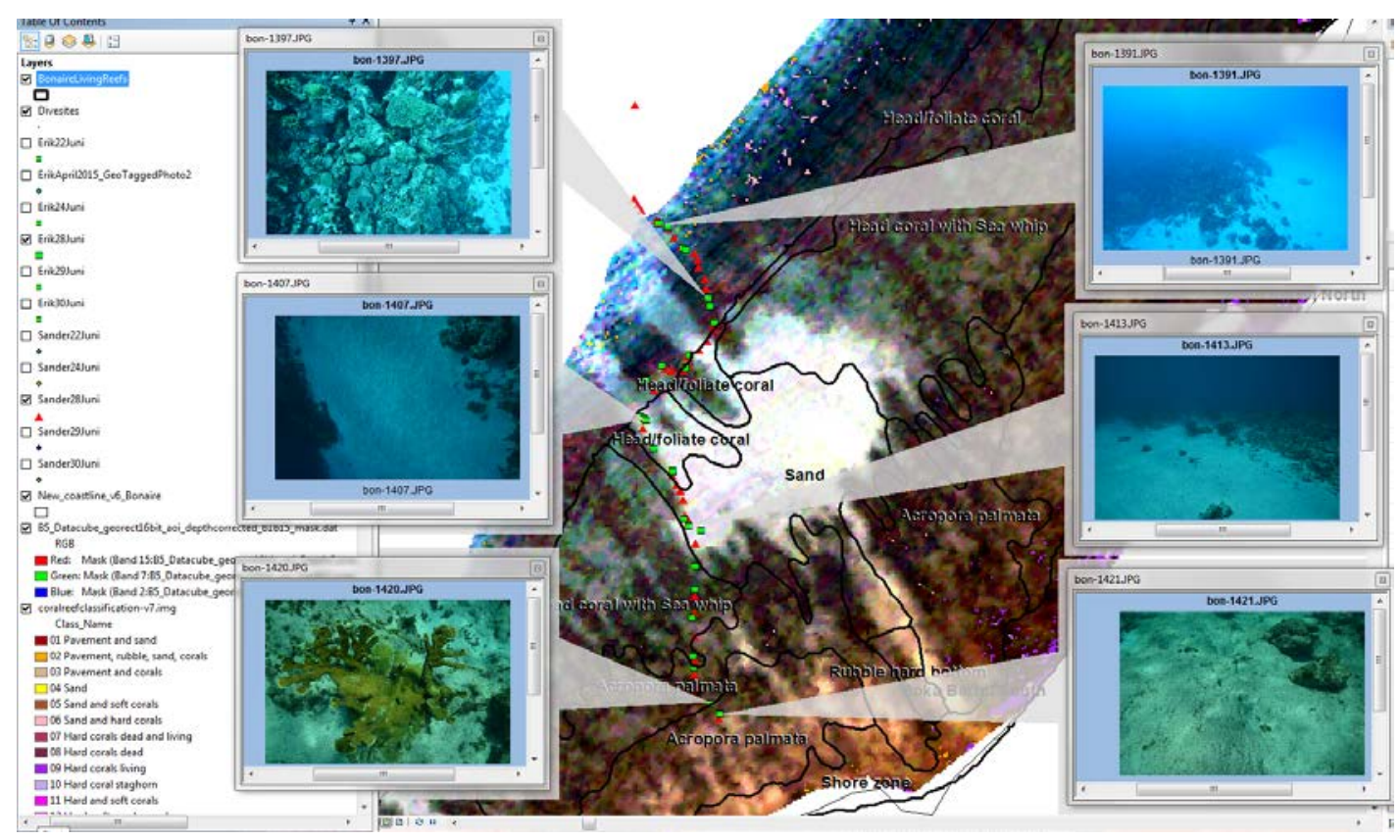

Figure 28 Hyperspectral data cube image (middle) with diving transect (dotted line) near Bartol South on 28th of June 2016, overlaid with Atlas of the Living Reefs (black lines) and images at certain points on the map. Left the classification from Van Duyl (1985).

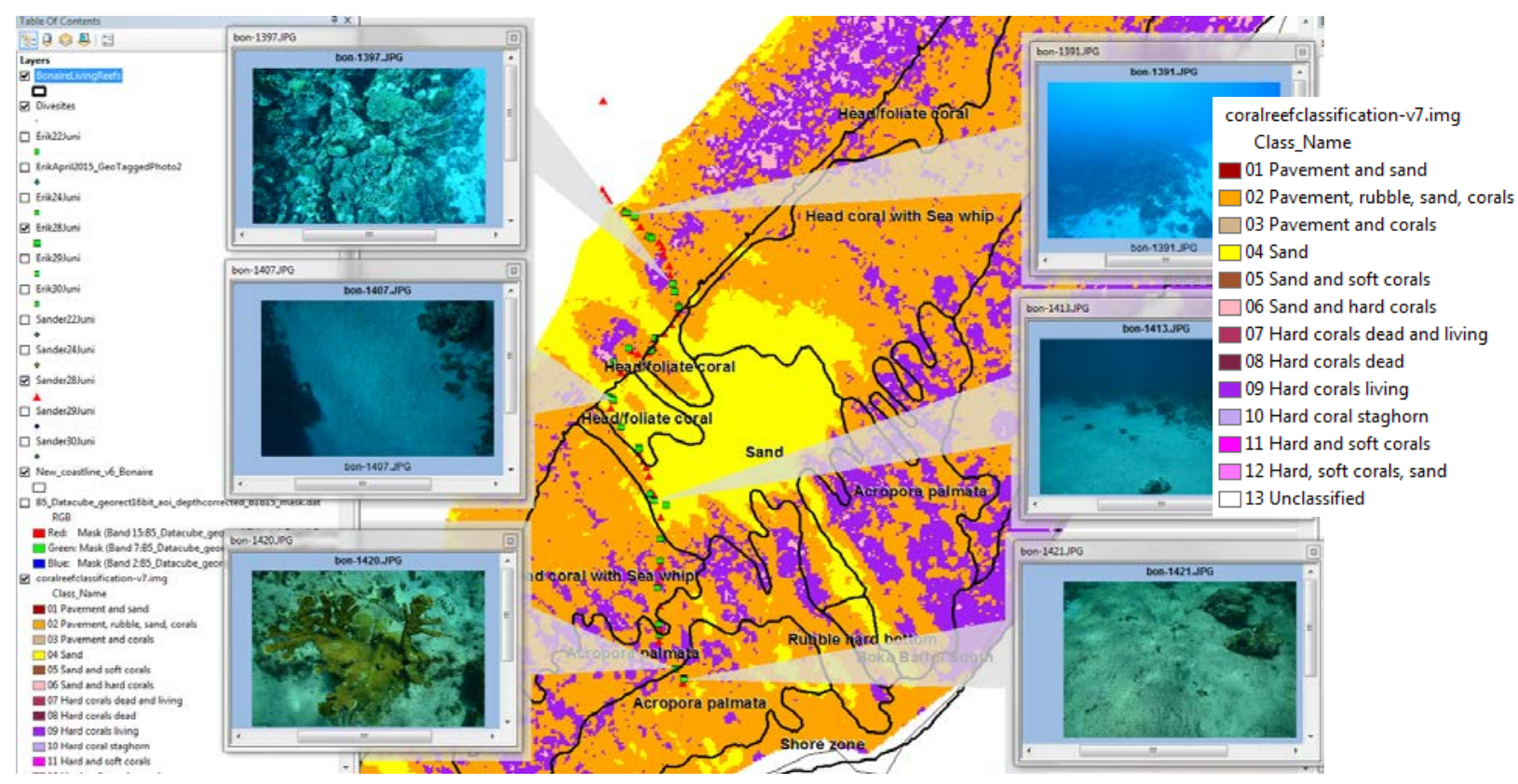

Figure 29 Same image as Figure 28, but now with the HCRC classification result. 


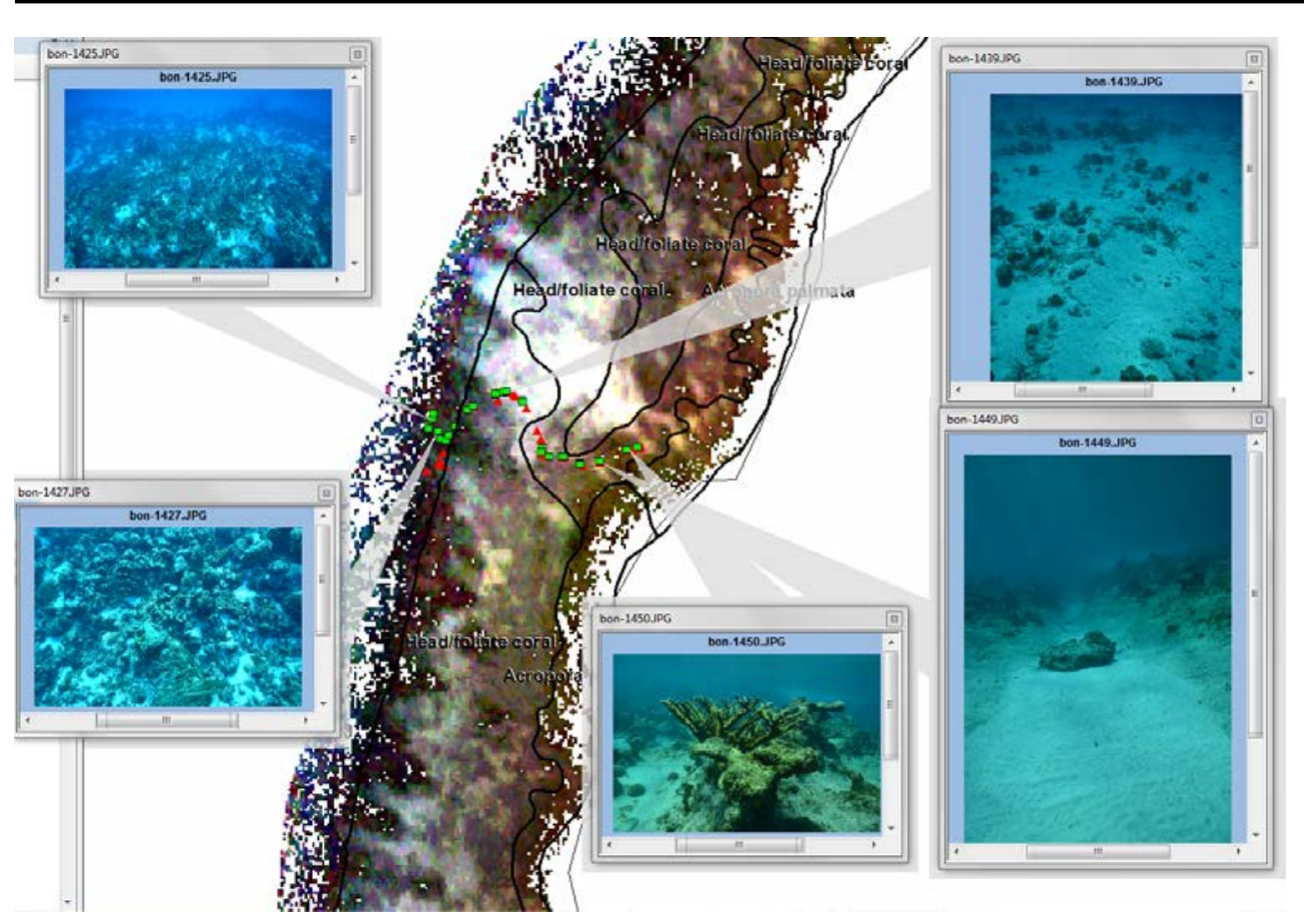

Figure 30 Hyperspectral data cube image with diving transect (dotted line) south of Playa Benge on 28th of J une 2016 overlaid with the areas from Van Duyl (1985, black lines).

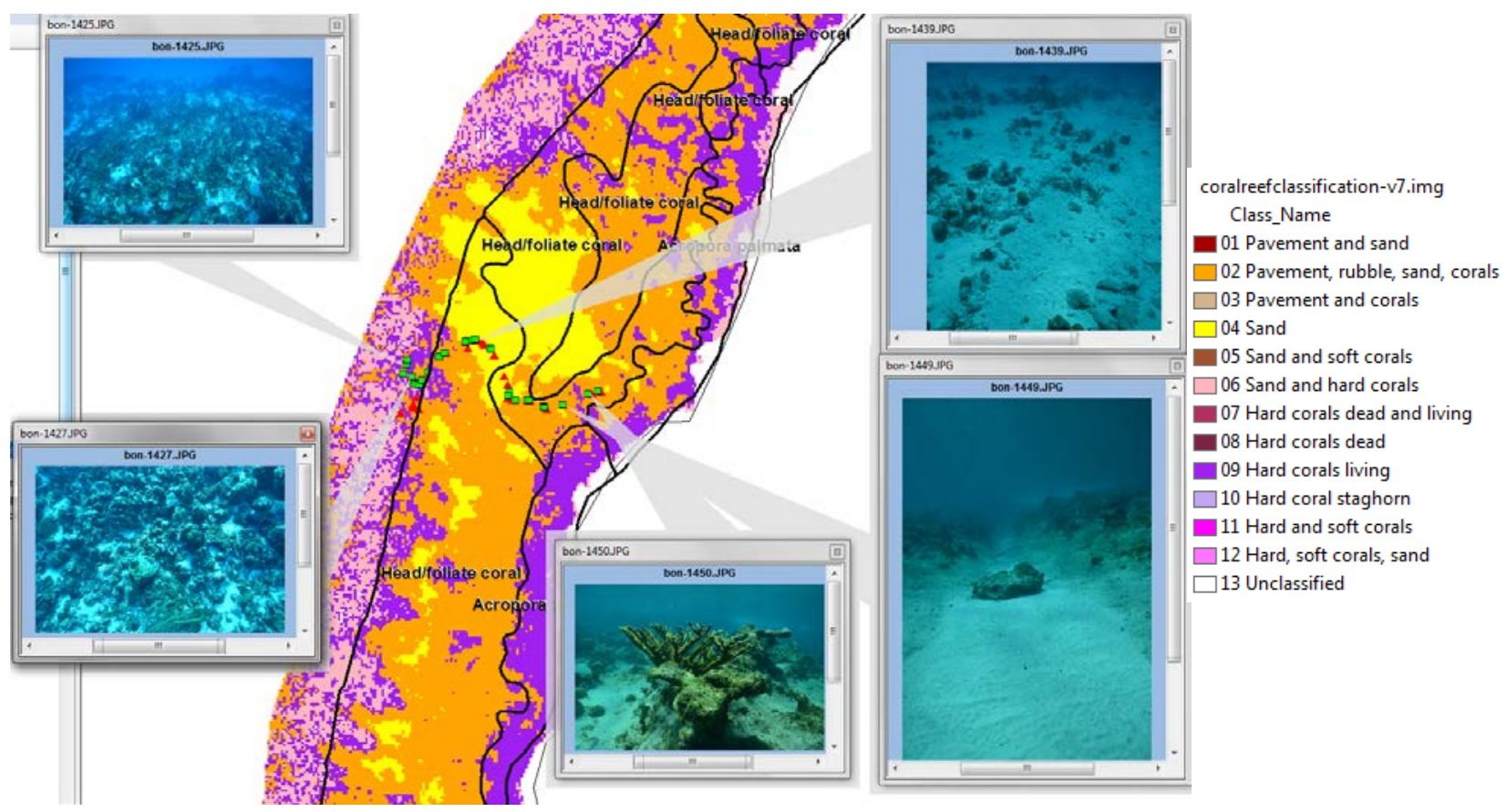

Figure 31 HCRC with diving transect south of Playa Benge on 28th of June 2016 overlaid with areas from Van Duyl (1985, black lines). 


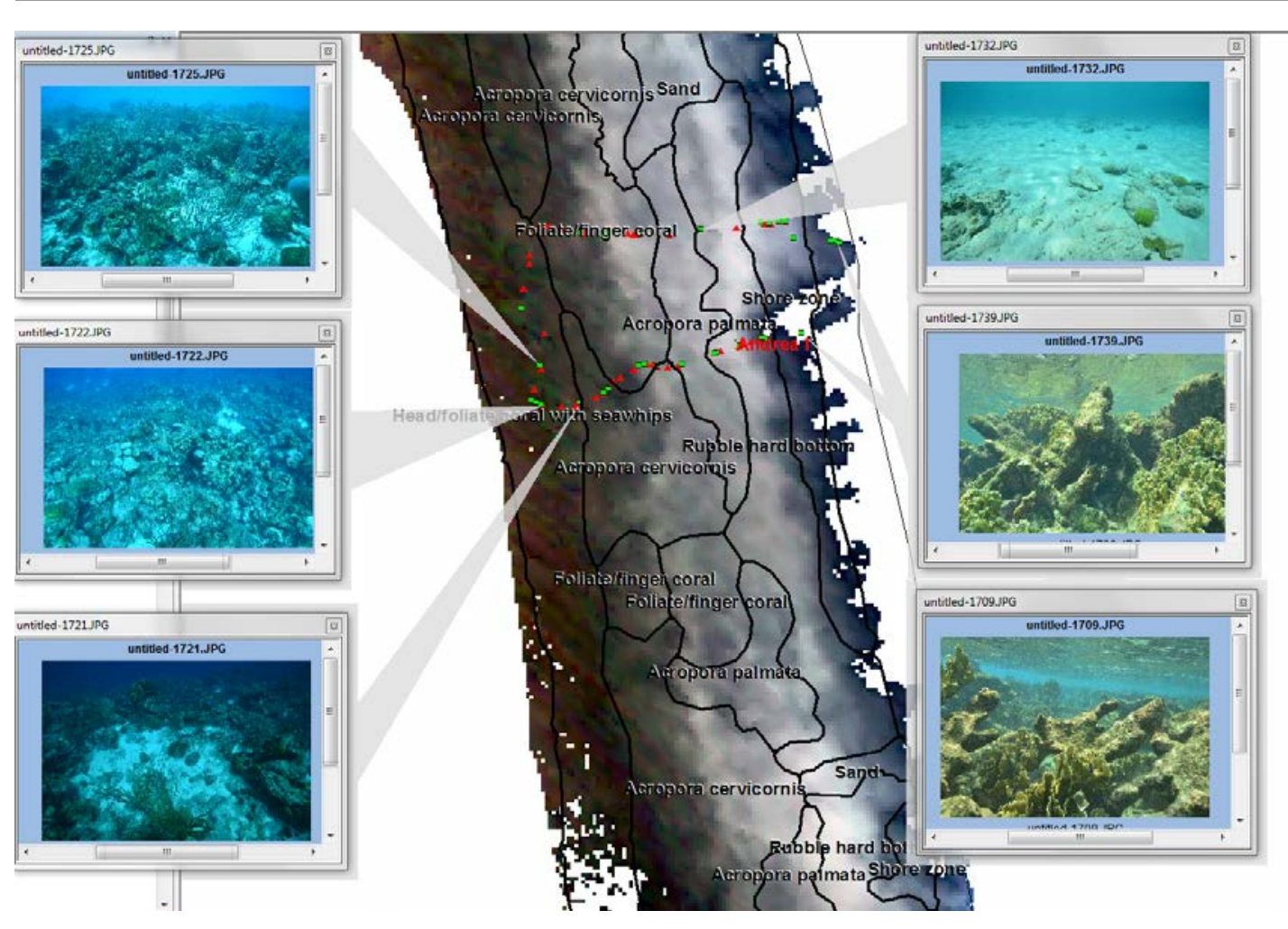

Figure 32 As Figure 30, but for Andrea I on 28th of J une 2016.
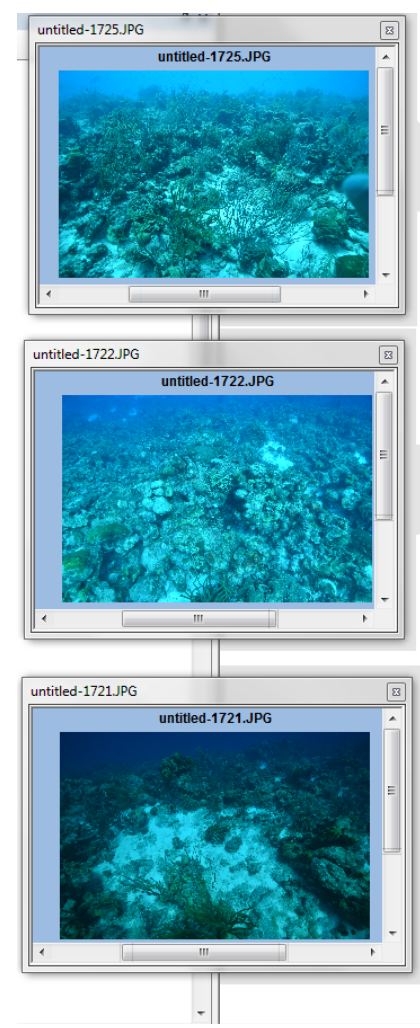
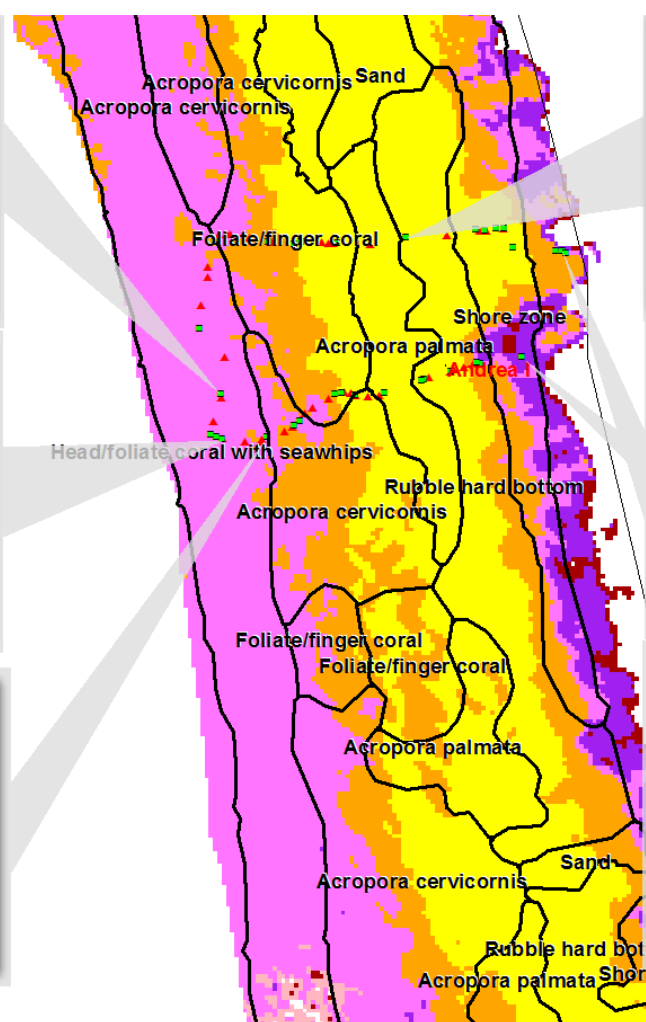

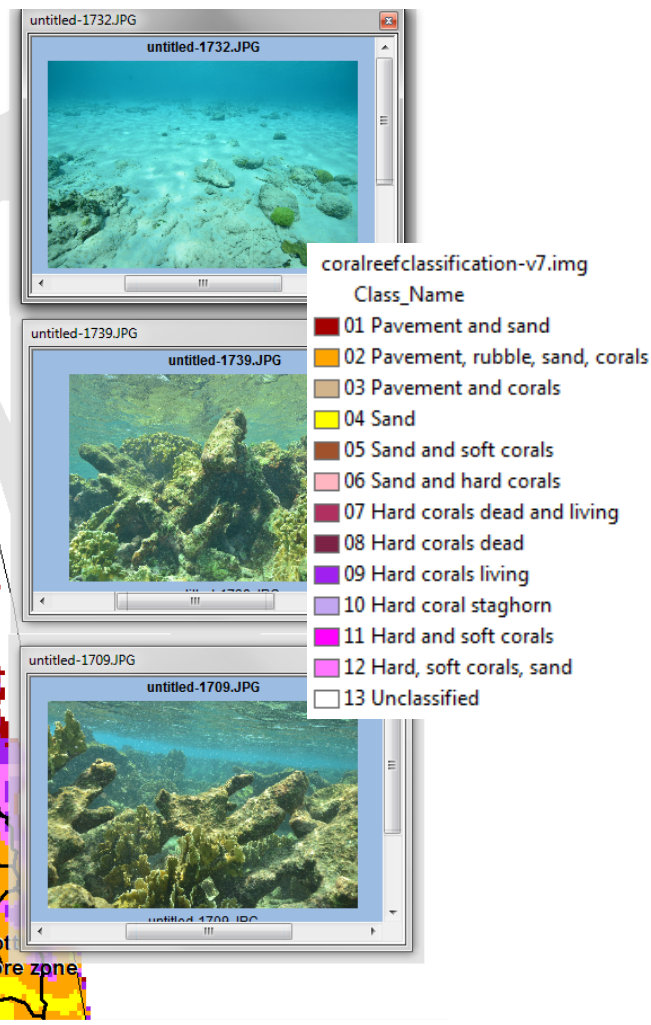

Figure 33 As Figure 31, but for Andrea I on 28th of J une 2016. 


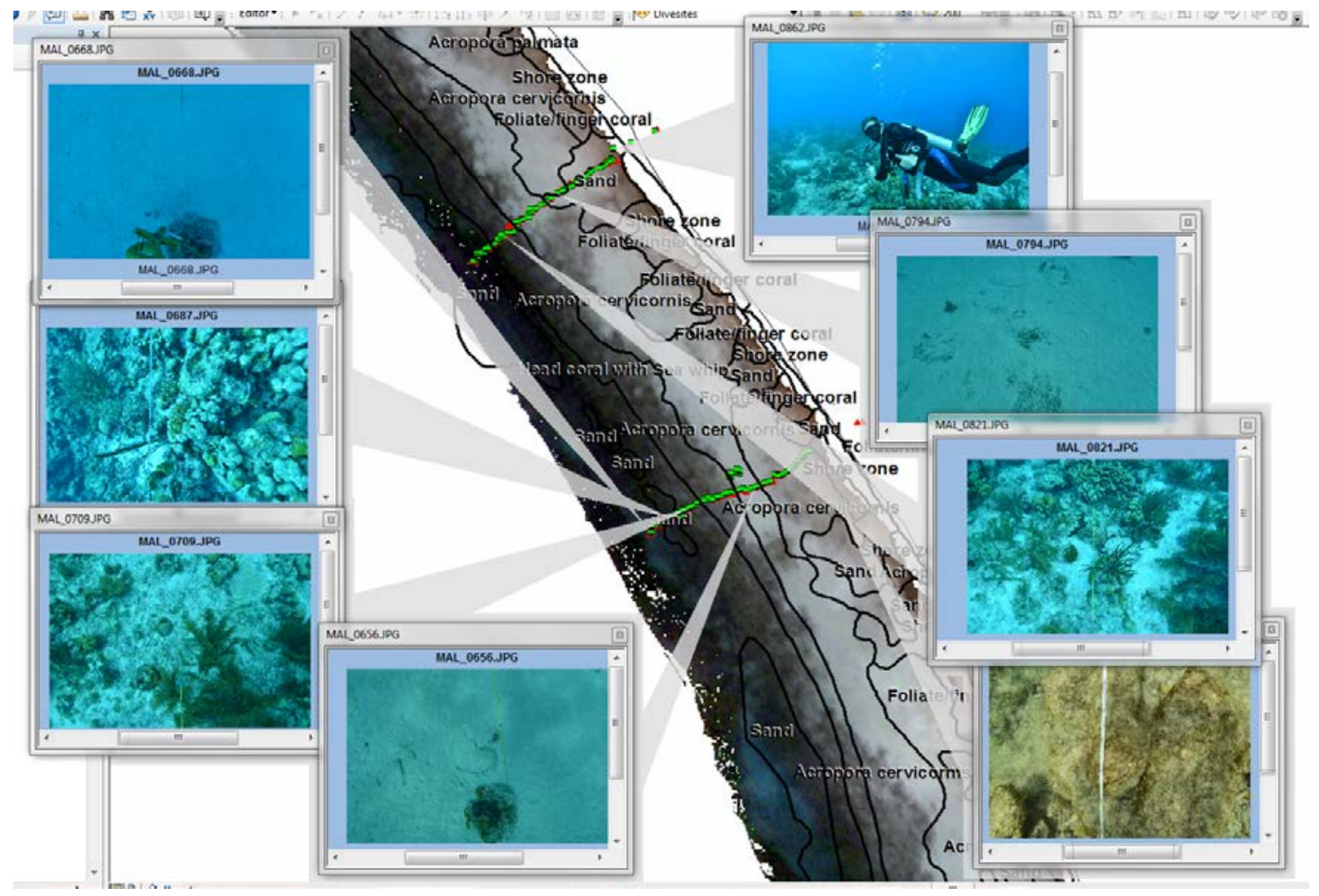

Figure 34 Hyperspectral data cube image with dive transect between Hilma Hooker and Angel City on 22 nd of June 2016 overlaid with the areas from Van Duyl (1985, black lines).

coralreefclassification-v7.img Class_Name

01 Pavement and sand

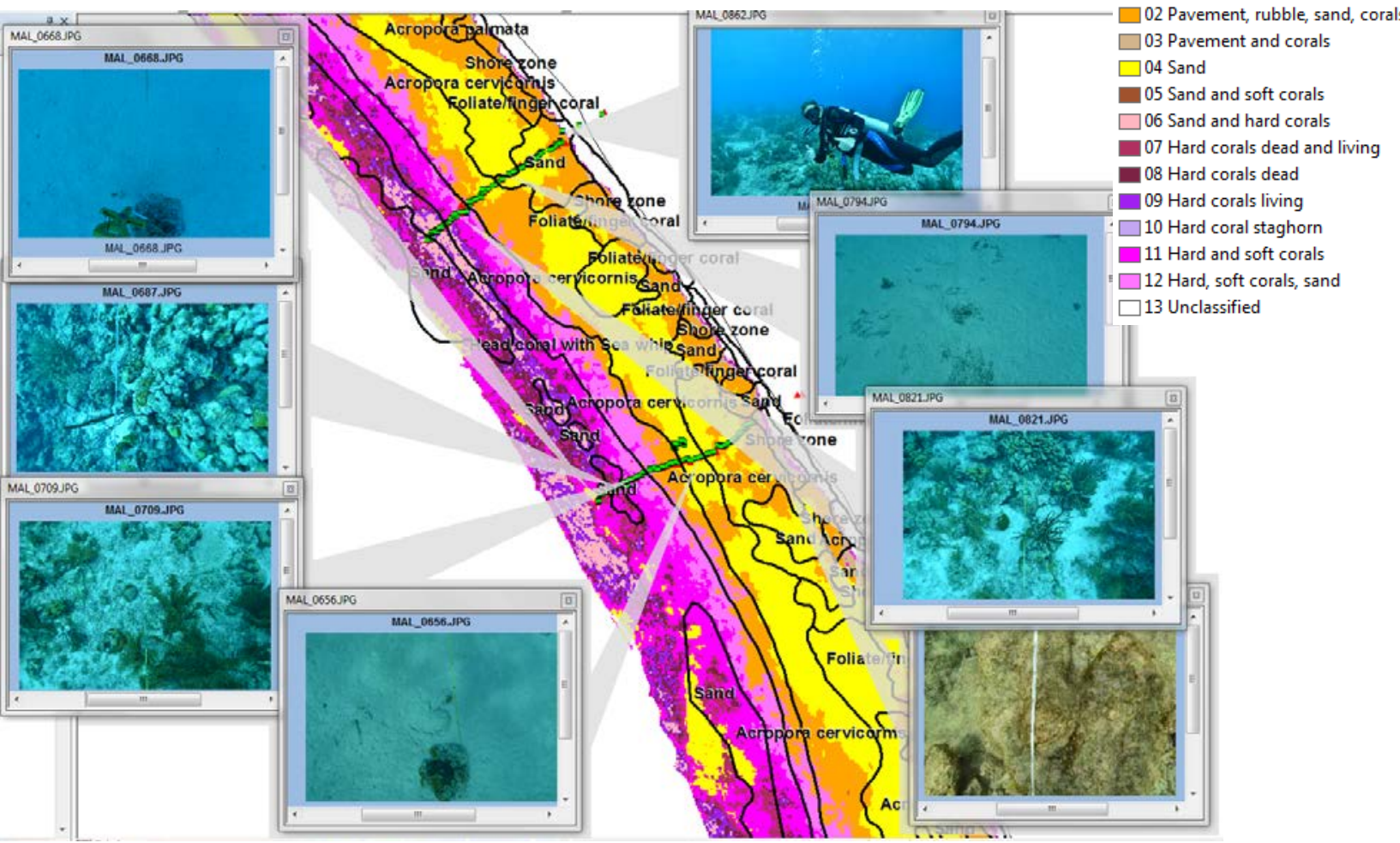

Figure 35 HCRC with diving between Hilma Hooker and Angel City on 22nd of J une 2016 overlaid with Van Duyl (1985) areas (black lines). 


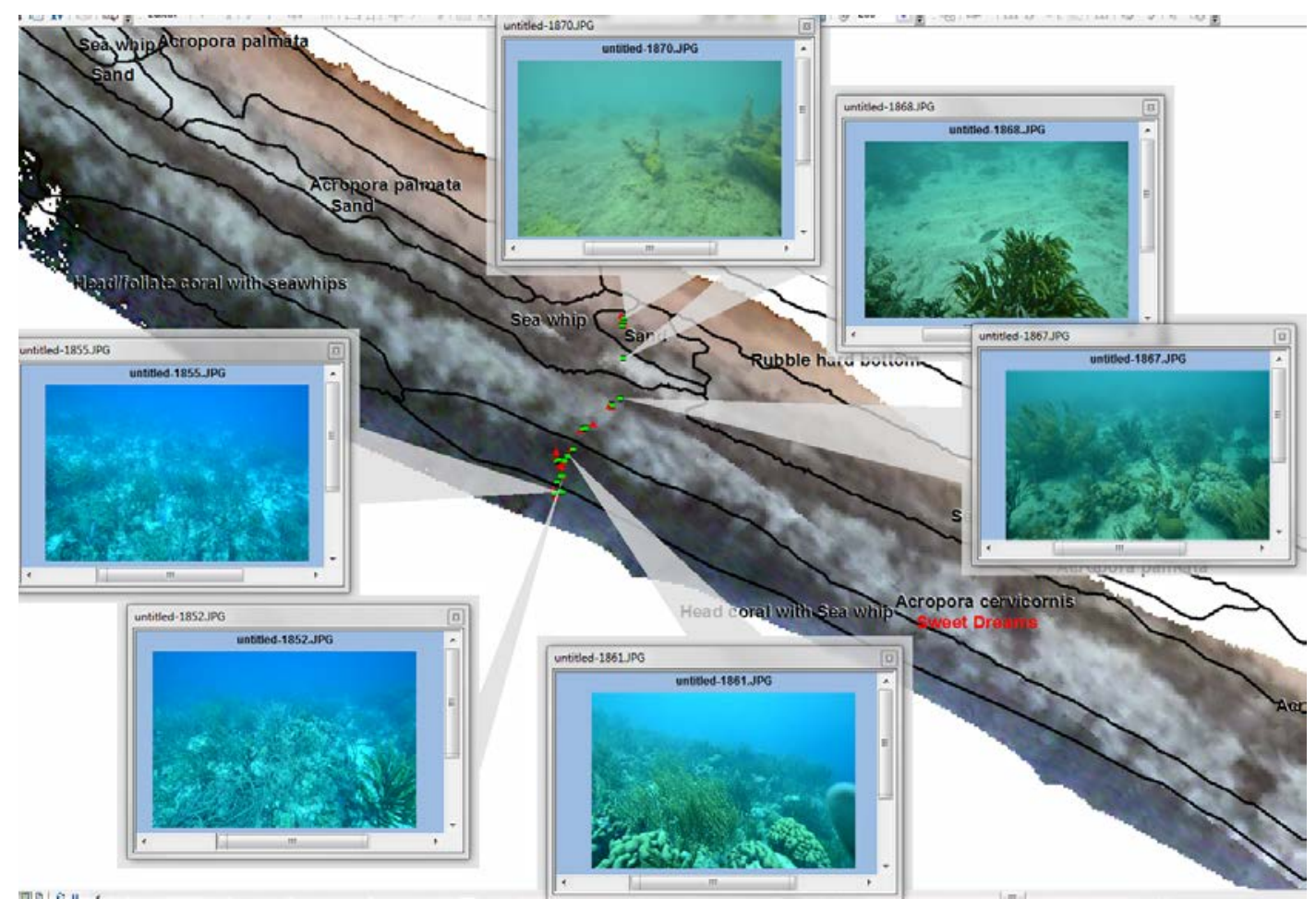

Figure 36 Hyperspectral data cube image with dive transect north of Sweat Dreams on 30th of June 2016 overlaid with Van Duyl (1985) areas (black lines).

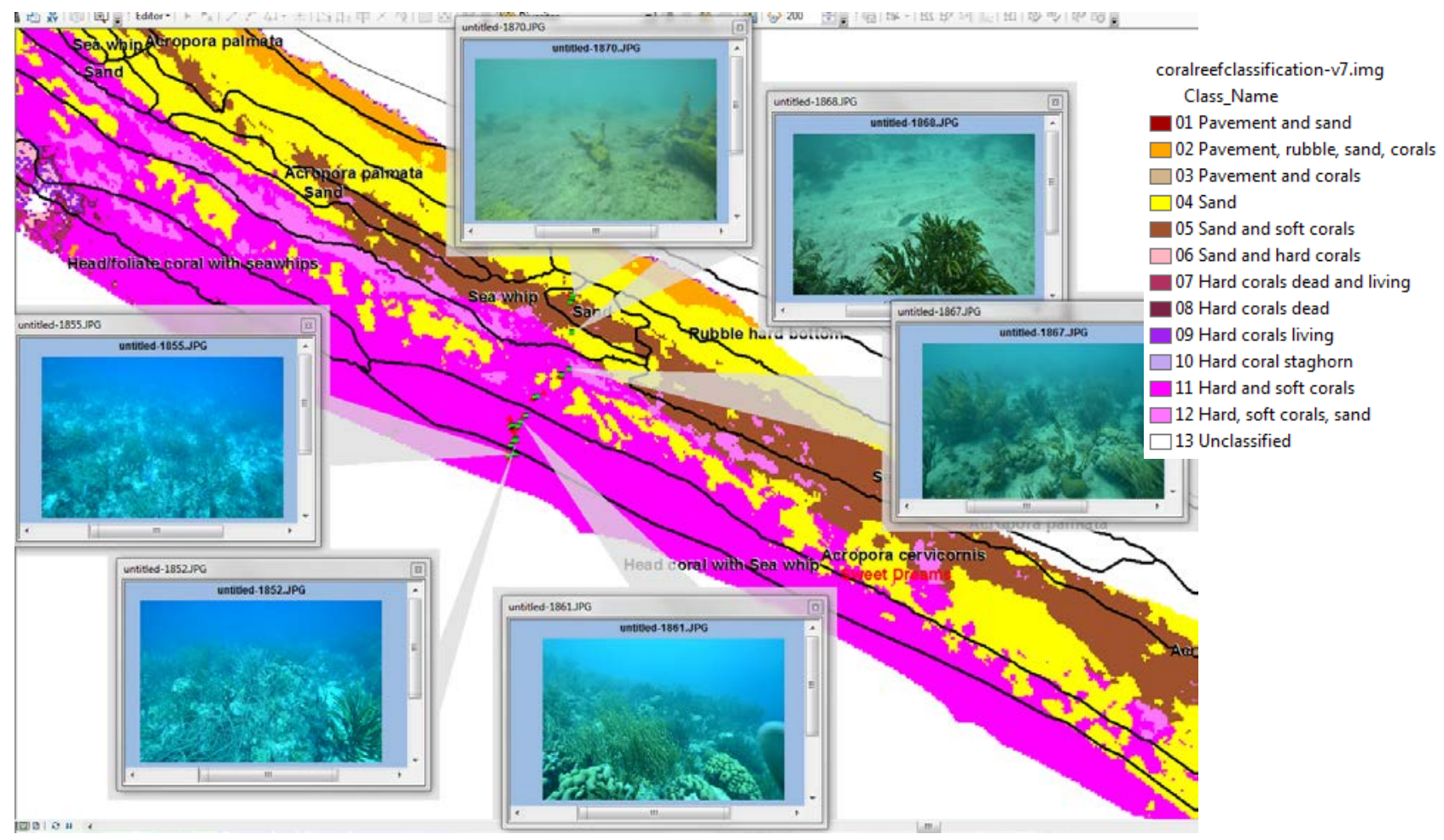

Figure $37 \mathrm{HCRC}$ including the dive transect North of Sweat Dreams on 30th of J une 2016 overlaid with Van Duyl (1985) areas (black lines).

It is still difficult to separate algae from corals and more groundtruthing would be necessary to increase the amount of confidence in the assessment of these categories. So far it remains impossible to say how much of the corals in a coral area are actually alive and how much is dead and covered by algae. However, we are confident in our comparison of the amount of sand in 1985 and 2013 (Table 2). 
Table 2

Comparison amount of sand in HCRC (2013) with the Atlas of the Living Reefs of Curacao and Bonaire (Van Duyl 1985).

\begin{tabular}{llccccc} 
Source & Class name & Total area & Klein Bonaire & Middle & North & South \\
Atlas Van Duyl & Sand & 71.4 & 25.2 & 14.9 & 3.4 & 27.8 \\
\hline HCRC & Sand & 112.7 & 18.4 & 13.7 & 30.7 & 49.9
\end{tabular}

Strikingly, the amount of sand has increased enormously since the early eighties, at the cost of stoney corals. Most likely this is to a large degree caused by the coral die-off after the White Band Disease in the mid eighties (Aronson \& Precht, 2001). In total the area of sand has increased with $58 \%$ in thirty years. And more strikingly is that the amount of sand has increased in the Northern region by a factor 10 , while this region is protected! On the other hand, the situation for Klein Bonaire has improved where it concerns the amount of sand. 


\section{Conclusions \& Recommendations}

It is possible to derive a spatially detailed coral reef classification from airborne hyperspectral data, but with a limited number of coral reef classes and with a limited extend from the coast on Bonaire. Only the first 15 hyperspectral bands in the violet-blue-cyan till the green range (Band $1=450.0 \mathrm{~nm}$ to Band $15=520.0 \mathrm{~nm}$ ) could be used for the coral reef classification due to the limited penetration of green and red light through the water. For the violet-blue spectral measurements a maximum depth of 20 30 meters could be reached. For a good water column correction of the hyperspectral data cube a detailed bathymetric model is needed. Unfortunately such a bathymetric model was missing for Bonaire, and was replaced by an extrapolated DEM from the land into to sea with the help of some depth point measurements in the coastal zone of Bonaire. A good bathymetric model would help to improve the accuracy of the coral reef classification.

The final hyperspectral Coral Reef Classification (HCRC) for Bonaire, has 12 benthic habitat classes in a narrow strip (on average 150 meters wide) along the coast of Bonaire (approximately $50 \mathrm{~km}$ long), with the Eastern coast missing, till a depth of approximately 20 - 30 meters. The total area covered by the HCRC is 693 ha. The HCRC is dominated by a few classes: 2 'pavement, rubble, sand and corals', 4 'sand', 9 'hard corals living', with respectively, 39\%, $21 \%$ and $15 \%$. So these 3 classes are already responsible for $75 \%$ of the coral reef. Unfortunately, we were not able to perform a quantitative validation to assess the accuracy of the individual classes.

Comparison with the underwater atlas of Bonaire and Curaçao (Duyl 1985) showed that the amount of sand has increased enormously since the early eighties, at the cost of hard corals. In total, the area of sand has increased with $58 \%$ in thirty years. And more strikingly is that the amount of sand has increased in the Northern region by a factor 10, while this region is protected! On the other hand, the situation for Klein Bonaire has improved where it concerns the amount of sand.

If there are opportunities to make a new coral reef classification for any area, it should not be based on diving only, since the delineation of the classes is not always accurate and it is too time-consuming. On the other hand, it should not only be based on airborne imagery with a high spatial resolution, due to the limited amount of benthic habitat classes that can be distinguished and no individual species can be detected. A future coral reef classification should be based on the integration of multispectral imagery in the violet-blue-cyan till green range corrected by a good bathymetric model and interpreted with the help of additional in-situ data. Future in-situ measurements should be ideally geotagged by accurate GPS recordings, to enable their exploitation of image interpretation. At this moment, it is in most cases not possible to have accurate GPS co-ordinates under water. Although some companies are starting now to offer underwater GPS positioning systems. 


\section{Acknowledgements}

We like to thank many different people that have helped us over the years to make this project possible. First of all, DCNA Nature for proving Sander Mücher a working place and housing during his sabbatical at Bonaire in 2016, and secondly STINAPA Bonaire for providing boat support. Bert Foks for making his plane (and boat) available and helping us with the rigging of the camera so we could take the best possible pictures. Willem Mouissie and Javier Boezem for documenting many of our successful (and sometimes less successful) endeavours to map and photograph Bonaire's reefs from the air. Roel van der Schoot for assisting with the GPS mapping and ground-truthing. Renate van Zanten and Haico van Heuzen for collecting sea depth measurements that enabled us to process a bathymetric model. 


\section{References}

Aronson R.B., Precht W.F. (2001). White-band disease and the changing face of Caribbean coral reefs. Hydrobiologia 460: 25-38.

Bak R.P., Nieuwland G., Meesters E.H. 2005. Coral reef crisis in deep and shallow reefs: 30 years of constancy and change in reefs of Curacao and Bonaire. Coral Reefs 24:475-479

De Bakker D.M., Meesters E.H., Bak R.P.M., Nieuwland G., Van Duyl F.C. (2016) Long-term Shifts in Coral Communities On Shallow to Deep Reef Slopes of Curaçao and Bonaire: Are There Any Winners? Frontiers in Marine Science 3

De Bakker D.M., van Duyl F.C., Bak R.P.M., Nugues M.M., Nieuwland G., Meesters E.H. (2017) 40 Years of benthic community change on the Caribbean reefs of Curaçao and Bonaire: the rise of slimy cyanobacterial mats. Coral Reefs: 1-13

Duyl FCv (1985) Atlas of thee living reefs of Curacao and Bonaire (Netherlands Antilles). Foundation for Scientific Research in Surinam and the Netherlands Antilles

Green, E. P., Mumby, P. J., Edwards, A. J., Clark, C. D. 2000. Remote Sensing Handbook for Tropical Coastal Management. Coastal Management Sourcebooks 3. Paris: UNESCO.

Lyzenga, D.R., 1981. Remote sensing of bottom reflectance and water attenuation parameters in shallow water using aircraft and landsat data (bahamas). international journal of remote sensing, 2, 71-82.

Mumby, P.J., Skirving, W., Strong, A.E., Hardy, J.T., Ledrew, E.F., Hochberg, E.J., Stumpf, R.P. \& David, L.T. 2004. Remote sensing of coral reefs and their physical environment. marine pollution bulletin, 48, 219-228.

Mumby, P.J., Clark, C.D., Green, E.P., Edwards, A.J., 1998. Benefits of water column correction and contextual editing for mapping coral reefs. International Journal of Remote Sensing, 19, 203-210.

Newman SP, Meesters EH, Dryden CS, Williams SM, Sanchez C, Mumby PJ, Polunin NVC (2015) Reef flattening effects on total richness and species responses in the Caribbean. J Anim Ecol 84:16781689

Nieto, P., 2013. Classifying benthic habitats and deriving bathymetry at the Caribbean Netherlands using multispectral Imagery. Case study of St. Eustatius. Thesis Report GIRS-2013-18, Wageningen University, $\quad$ the Netherlands, $\quad 98$ pp.

Suomalainen, J. , Anders, N., I qbal, S., Roerink, G., Franke, J., Wenting, P., Hünniger, D., Bartholomeus, H., Becker, R., Kooistra, L., 2014. A Lightweight Hyperspectral Mapping System and Photogrammetric Processing Chain for Unmanned Aerial Vehicles. Remote Sens. 2014, 6(11), 11013-11030; doi: 10.3390/rs61111013.

Van Duyl, F., 1985. Atlas of the living reefs of Curacao and Bonaire (Netherlands Antilles). Foundation for Scientific Research in Surinam and the Netherlands Antilles, cjo Zool. Laboratory, Plompetorengracht 9, 3512 CA Utrecht, The Netherlands, and The Atlantic Reef Committee (ARC), Fisher Island Station, Miami Beach, Florida 331 39, U.S.A.

Wahba, G. 1990. Spline models for Observational data. Paper presented at CBMS-NSF Regional Conference Series in Applied Mathematics. Philadelphia: Soc. Ind. Appl. Maths.

WKICS (2013) The Economics of Ecosystems and Biodiversity on Bonaire. What's Bonaire's Nature Worth?Edwards, A.J., 1999. applications of satellite and airborne image data to coastal management. in: UNESCO (ed.). Paris. 
Wageningen Marine Research

$\mathrm{T}+31(0) 317480900$

E: marine-research@wur.nl

www.wur.eu/marine-research

Visitors' address

- Ankerpark 271781 AG Den Helder

- Korringaweg 5, 4401 NT Yerseke

- Haringkade 1, 1976 CP IJ muiden
Wageningen Marine Research is the Netherlands research institute established to provide the scientific support that is essential for developing policies and innovation in respect of the marine environment, fishery activities, aquaculture and the maritime sector.

\section{Wageningen University \& Research:}

is specialised in the domain of healthy food and living environment.

\section{The Wageningen Marine Research vision}

'To explore the potential of marine nature to improve the quality of life'

\section{The Wageningen Marine Research mission}

- To conduct research with the aim of acquiring knowledge and offering advice on the sustainable management and use of marine and coastal areas.

- Wageningen Marine Research is an independent, leading scientific research institute

Wageningen Marine Research is part of the international knowledge organisation Wageningen UR (University \& Research centre). Within Wageningen UR, nine specialised research institutes of the Stichting Wageningen Research Foundation have joined forces with Wageningen University to help answer the most important questions in the domain of healthy food and living environment. 